\title{
Principio de destino: alcance de los mecanismos para el recaudo del IVA en la prestación transfronteriza de servicios
}

\section{Principle of Destination: Reach of the VAT collection mechanisms in cross-border provision of services}

\author{
JUdith PaVa RAMÍREZ ${ }^{1}$
}

\section{Resumen \\ La Reforma Tributaria Estructural, Ley 1819 de 2016, introdujo modificaciones importantes en el hecho generador del IVA, entre estas, la del literal b) del artículo 420 del Estatuto Tributario, que incorporó la aplicación del principio de destino en la prestación de servicios desde el exterior, entendiendo que estas se encuentran suje- tas a imposición cuando el destinatario y/o usuario del servicio estén localizados en el territorio nacional, adecuando de esta forma}

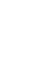


Palabras clave: IVA, Comercio electrónico, Economía digital, Localización, Territorialidad, Servicios electrónicos.

\section{Abstract \\ The Structural Tax Reform, Law 1819 of 2016, introduced important changes in VAT generating events, among them, the one described in literal b) of article 420 of the Tax Statute, which incorporated the appli- cation of the principle of destination in the provision of services from abroad, taking into consideration that they are subject to taxation when the recipient and / or user of the service is located in domestic territory, thus, adapting the tax rule to new events, previously free of taxes, including the digital economy.}

One of the challenges that the Tax Administration must face is to ensure the effectiveness of tax collection when the individual responsible for VAT payments is the provider of the service abroad. This topic is addressed in this paper by means of the analysis of the collection mechanisms suggested by the $\mathrm{OECD}$, around which, alternative solutions are proposed.

Keywords: VAT, Electronic commerce, Digital economy, Location, Territoriality, Electronic services.

\section{Introducción}

Desde el punto de vista económico, el fenómeno de la globalización ha sido promovido principalmente por la integración de las economías de los países y, con ello, un mercado de bienes, capitales y servicios cada vez más competitivo, con sistemas de producción integrados, donde las innovaciones tecnológicas han influido de manera significativa a este desarrollo, con el avance en las telecomunicaciones, en los sistemas de información y en la movilidad de las personas alrededor del mundo, que desdibujan el concepto de frontera y la distancia deja de ser un impedimento para las operaciones comerciales, abriendo paso a nuevas formas de hacer negocios.

Es así como el ritmo creciente de las tecnologías de la información y la comunicación y la gran afluencia del internet en nuestra sociedad han generado la ascendente transformación de la Economía tradicional en Economía digital, en la que el concepto de lo físico va desapareciendo y se incorpora en lo virtual, incrementándose de esta forma varios modelos de negocios a través de la red ${ }^{2}$.

Desde una perspectiva fiscal, resultan relevantes ciertos aspectos fundamentales o características de la Economía digital, entre ellos, la movilidad, la importancia de los

${ }^{2}$ Como lo expone la OCDE, "La economía digital se caracteriza por basarse, como ninguna otra, en activos intangibles, por el uso masivo de datos (...) y por la dificultad de determinar la jurisdicción bajo la que tiene lugar la creación de valor. Todo esto plantea cuestiones fundamentales sobre cómo pueden las empresas añadir valor y obtener beneficios y sobre cómo se relaciona la economía digital con los conceptos de fuente y residencia para la caracterización de los ingresos para fines impositivos", tomado de Proyecto OCDE/G20 de Erosión de la Base Imponible y Traslado de Beneficios. Cómo abordar los desafíos fiscales de la Economía Digital. ACCIÓN 1: Objetivo del 2014. 
datos, los efectos de la red, la proliferación de modelos de negocio multilaterales, una tendencia hacia el monopolio u oligopolio y la volatilidad, así como sus modelos de negocios, como, por ejemplo, varias modalidades de comercio electrónico, tiendas de aplicaciones, publicidad en línea, computación en la nube, plataformas participativas en red, negociación de alta frecuencia y servicios de pago en línea, asuntos que generan dificultades para la aplicación de las normas fiscales actuales y exigen concebir medidas exhaustivas para hacerles frente (OCDE Acción BEPS 1,2014).

Este novedoso fenómeno de Economía digital ha planteado desafíos de cambios en la política fiscal a nivel interno de los Estados, así como a nivel internacional, para hacer frente a los efectos de la internacionalización dada la gran movilidad de las bases imponibles, que exige que las normas se adapten a las condiciones actuales e impidan prácticas injustas o ilegales de erosión de la base imponible y el traslado de beneficios ${ }^{3}$.

Colombia no ha sido ajena a estos retos. Con la reforma tributaria estructural aprobada mediante la Ley 1819 de diciembre de
2016, introduce cambios importantes en la tributación indirecta aplicada a la prestación de servicios transfronterizos, a fin de adecuar la normatividad fiscal a fenómenos que se encontraban ajenos a supuestos de tributación. En tal sentido, modifica la regla general que estaba vigente, donde el Impuesto al Valor Agregado (en adelante IVA), se causaba únicamente en los servicios prestados en Colombia y, por excepción, algunos prestados desde el exterior, produciendo un cambio en el aspecto espacial del hecho generador del IVA, para incluir todos los servicios prestados desde el exterior cuando estos se entienden realizados en el territorio colombiano, atendiendo el "principio de destino"4.

En cuanto al recaudo del IVA, la misma ley en comento modifica el numeral 3 y adiciona el numeral 8 del Artículo 437-2 del Estatuto Tributario (en adelante ET), relacionado con los agentes de retención en el IVA. En el numeral 3, fija la regla general de recaudo del impuesto vía retención para los servicios prestados desde el exterior, cuando el destinatario del servicio es una persona del régimen común y será esta quien practique la retención. En la adición del numeral 
8, establece el recaudo vía retención solo cuando se trate de la prestación de servicios electrónicos o digitales y cuando los prestadores de estos servicios desde el exterior (los que defina la DIAN), incumplan con las obligaciones de recaudar, declarar y pagar el IVA, evento en el cual actuarán como agentes retenedores en el momento del pago, los bancos emisores de tarjetas de crédito y débito, los vendedores de tarjetas prepago, los recaudadores de efectivo a cargo de terceros y los demás que designe la DIAN.

De acuerdo con este marco jurídico, surgen varios interrogantes respecto a las condiciones subjetivas, los mismos que van a ser el objeto de esta investigación; el primero de ellos hace referencia a la responsabilidad asignada a los proveedores del exterior de recaudar, declarar y pagar el impuesto ${ }^{5}$, cuando el servicio no sea prestado a los responsables del régimen común; de ahí que surge el problema a investigar con el siguiente planteamiento: ¿Cómo se efectuará el recaudo del IVA en los servicios señalados en el numeral 8 del Artículo 437-2 del ET cuando el consumidor no sea del régimen común, si los proveedores del exterior como responsables de efectuar el recaudo lo hacen de forma voluntaria y en caso de incumplimiento cómo se haría efectiva la sanción?

Una vez efectuado el planteamiento del problema a investigar generado por las dudas que suscita la pretensión impositiva, vista desde su practicidad, el objetivo principal no está enfocado en hacer solo un análisis crítico de la eficacia en el recaudo, sino que va más allá de este razonamiento y pretende encontrar respuesta sobre la existencia de mecanismos que se puedan sugerir para que el recaudo del impuesto no quede a merced de la voluntad del proveedor extranjero, por lo tanto, se presenta una primera propuesta cuyo objetivo es mitigar el riesgo de incumplimiento por parte del proveedor del exterior y una segunda propuesta, encaminada a la búsqueda de una solución comunitaria en el seno de la CAN.

En este contexto, el presente artículo tiene como objetivo adentrarnos en la definición, aspectos legales y el marco tributario que rige el comercio electrónico, para luego analizar la prestación de servicios como hecho generador del IVA y cómo opera este mecanismo en otros países y, por último, plantear una alternativa de solución que permita la efectividad en el recaudo, conscientes de que se trata de un granito de arena frente a los grandes esfuerzos que han hecho el Estado y, en especial, la administración tributaria por encontrar soluciones viables a este desafío que impone la economía digital.

\section{El comercio electrónico}

\section{A. Generalidades}

El concepto de comercio se refiere a la transacción que implica la compra y/o venta de un producto a través de un local o espacio donde se lleva a cabo la actividad comercial, mientras que el comercio electrónico vincu-

${ }^{5}$ Se aplicaría principalmente para la prestación de servicios B2C, que, por sus siglas en inglés significa business-to-consumer, y traducido expresa "de empresa al consumidor; destinado al consumidor final (OCDE Acción BEPS 1, ibídem). 
la a las operaciones comerciales a través de medios electrónicos, principalmente internet, conocido también como e-commerce, es decir, que tanto el proveedor de los bienes y servicios como el cliente interactúan electrónicamente sin requerir de un contacto físico directo.

El comercio electrónico es definido por la OCDE (2011) como la compraventa de bienes o servicios, efectuada a través de redes informáticas mediante métodos específicamente diseñados con el objeto de recibir o hacer pedidos, sin que se requiera que el pago y entrega final de los bienes o servicios tengan que ser realizados necesariamente por esa vía (p. 82).

El comercio electrónico involucra la realización de negocios online, que significa vender/comprar productos y prestar servicios a través de sitios ubicados en la red, independientemente del canal por el que posteriormente circule el producto o servicio.

Existen varios tipos de comercio electrónico clasificados en función de los agentes que participan en la relación comercial, cuya definición, según lo ha ilustrado la ONUUNCTAD (2015), es la siguiente:

B2B: representan la mayor parte del comercio electrónico. Se refiere a las transacciones entre empresas, por ejemplo, entre un fabricante y un mayorista o entre un mayorista y un minorista.
B2C: se trata de ventas realizadas a consumidores por empresas dedicadas exclusivamente al comercio electrónico y por empresas minoristas o manufactureras tradicionales con presencia física y que añaden un canal de ventas en línea.

C2C: puede considerarse como la versión moderna de utilizar la sección de anuncios clasificados de publicidad en un periódico local o ir a una subasta. Abarca plataformas de subasta en línea (por ejemplo, eBay o Taobao) y las ventas dentro de comunidades en línea.

B2G: estas transacciones son similares a las B2B, salvo que en este caso el comprador es una entidad gubernamental, como sucede en la contratación pública electrónica (p.4).

Otra clasificación de comercio electrónico a tener en cuenta cuando se establece el tipo de tributación es la que se yuxtapone a las distintas figuras impositivas: i) offline: comprende la contratación por vía electrónica de prestaciones y la entrega de bienes materiales o tangibles o de servicios no prestados por vía electrónica ${ }^{6}$; ii) online: recoge los servicios prestados por medios electrónicos, que incluiría tanto los servicios como los productos en formato digital, y en el que la oferta y aceptación del producto se realiza en su totalidad por medios electrónicos.

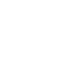

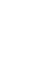




\section{B. Tratamiento legal en Colombia del comercio electrónico}

En Colombia, la creación normativa del comercio electrónico se da con la expedición de la Ley 527 de 1999, que define y reglamenta el acceso y uso de los mensajes de datos, del comercio electrónico y de las firmas digitales. Bajo esta norma se construye la base para la implementación del proceso administrativo electrónico, en la que se definen los conceptos y principios sobre la seguridad, eficacia y validez de los actos administrativos a través de medios electrónicos y a su vez contempla la regulación de la utilización de dichos medios.

Uno de los mayores alcances de esta ley fue otorgarles reconocimiento jurídico a los documentos electrónicos, similar al que tienen los documentos en papel como pruebas en procesos legales. Así mismo, introduce la figura de la firma digital y aspectos como el transporte de mercancías derivado de una transacción electrónica, y le dedica un capítulo completo a las entidades de certificación y los certificados digitales.

Otro avance se dio con la expedición de la Ley 1341 de julio de 2009, que define los principios y conceptos sobre la sociedad de la información y la organización de las tecnologías de la información y las comunicaciones TIC y crea la Agencia Nacional del Espectro.

\section{Recomendaciones de la Organización para la Cooperación y Desarrollo} Económico (OCDE)

Aunque existen otros organismos e instituciones a nivel internacional que se han ocupado del tema del comercio electrónico y han emitido informes importantes sobre el asunto, se analizarán solamente las recomendaciones que ha expuesto la OCDE, considerando que Colombia, según lo expresó el presidente de la República, se encuentra en la "recta final" de las negociaciones para acceder a este organismo por solicitud que hiciera en el año 2013 (Portafolio, 2017). La decisión de abrir formalmente la discusión de acceso para Colombia la adopta el Consejo de la OCDE en mayo de 2013, y en septiembre de ese mismo año, entrega de manera oficial la hoja de ruta con los términos y condiciones del proceso de acceso.

La OCDE es una de las organizaciones internacionales más activas en la promoción del comercio electrónico. Desde el año 1997 llegó a la conclusión de que dada la problemática en materia fiscal que genera esta nueva forma de hacer negocios, este era el organismo multilateral más propicio y adecuado para coordinar los trabajos y discusiones que en esta materia debían realizarse.

Es así como en diversas oportunidades se ha ocupado del tema, siendo de gran trascendencia lo refrendado en la conferencia de Ottawa en octubre de 1998, titulada "Un mundo sin fronteras: identificación del potencial del comercio electrónico", con la adopción del marco tributario que ha venido siendo aceptado desde entonces, conviniendo que los principios tributarios que aplican al comercio convencional pueden y deben aplicarse al comercio electrónico, no siendo necesaria la creación de nuevas figuras que puedan resultar discriminatorias.

Así mismo, refiriéndose de manera específica a los tributos sobre el consumo, señalaba que la mejor opción es el gravamen en 
el lugar de consumo, no debiendo tratarse a los productos digitalizados como «bienes». asegurar su progreso paralelo a los avances tecnológicos y comerciales.
En este sentido, de acuerdo con el documento de la OCDE (1998), el conjunto de principios fiscales aprobados y que han de aplicarse al comercio electrónico son los siguientes: neutralidad, eficiencia, seguridad jurídica y simplicidad, equidad y eficacia.

$\checkmark$ Neutralidad: el tratamiento entre el comercio tradicional y el electrónico debe ser el mismo, toda vez que, a pesar de que se emplean medios distintos, convencionales o informáticos, los dos constituyen formas del mismo fenómeno y, por tal razón, no deben estar sometidos a una carga tributaria diferenciada.

$\checkmark$ Eficiencia: los costos derivados del cumplimiento de las obligaciones fiscales para los contribuyentes, así como el costo de gestión para la administración tributaria deben ser los mínimos posibles.

$\checkmark$ Seguridad jurídica y simplicidad: las normas deben ser de fácil comprensión y sencilla aplicación, de manera que los contribuyentes puedan conocer por anticipado las consecuencias fiscales de una operación y, en particular, cuándo, dónde y cómo se declara el impuesto.

$\checkmark$ Equidad y eficacia: la imposición debe dar como resultado el valor correcto de impuesto debido y en el momento oportuno, reduciendo al máximo las posibilidades de fraude y de evasión fiscal, velando para que las medidas adoptadas en tal sentido sean proporcionales a los riesgos expuestos.

$\checkmark$ Flexibilidad: los sistemas tributarios deben ser flexibles y dinámicos para
Después de Ottawa el Comité de Asuntos Fiscales de la OCDE (CAF), en relación con los impuestos sobre el consumo, desarrolló un ambicioso programa de trabajo con el fin de dar impulso a lo logrado en Ottawa y consideró que se debía hacer a través de varios grupos consultivos. Producto de esta tarea del CAF, se publicaron en el año 2003 las "Directrices sobre Comercio Electrónico (2003b)", junto con la Guía de Impuestos sobre el Consumo (OCDE 2003c, e y f), que consta de tres documentos con orientaciones y recomendaciones sobre la aplicación práctica de las directrices. El principio rector de estas directrices es el sometimiento a gravamen de las operaciones transfronterizas de comercio electrónico con arreglo al principio de destino (OCDE, 2014), en el que se grava únicamente el consumo final en el país en que se considera tiene lugar efectivamente el consumo, las exportaciones no están sujetas a gravamen, pero tributando las importaciones sobre la misma base y a los mismos tipos que los suministros a nivel interno.

De igual modo, gobiernos de todo el mundo y la sociedad civil en general manifestaron su preocupación por la planificación fiscal llevada a cabo por empresas multinacionales, por la forma en que se aprovechan de las lagunas en la interacción entre los distintos sistemas tributarios para disminuir artificialmente sus bases imponibles o trasladar los beneficios a países o territorios de baja tributación y, en respuesta a esta preocupación, en julio de 2013 la OCDE/ G20 publicó un "Plan de acción contra la erosión de la base imponible y el traslado de beneficios", denominado "Plan de acción 
BEPS", que desarrolla 15 áreas estratégicas de trabajo concebidas para luchar contra el referido problema BEPS a través de una serie de recomendaciones técnicas (OCDE, 2015).

La Acción 1 de dicho "Plan de Acción BEPS" pretende abordar los desafíos fiscales de la Economía digital, identificando las principales dificultades que esta plantea para la aplicación de las normas fiscales internacionales existentes y desarrollando opciones detalladas para abordar estos obstáculos, con un enfoque holístico y teniendo en cuenta tanto impuestos directos como indirectos.

Otro instrumento jurídico en el ámbito del IVA emitido por la OCDE y que sirve de referencia a los países para diseñar e implementar su legislación sobre este impuesto indirecto, son "Las Directrices internacionales sobre IVA", aprobadas por el Consejo de la OCDE en septiembre de 2016 como un estándar mundial para el tratamiento del IVA en el comercio internacional de servicios e intangibles. El objetivo principal de estas directrices es reducir la incertidumbre y los riesgos de la doble imposición y no imposición involuntaria que resultan de las inconsistencias en la aplicación del IVA en un contexto transfronterizo.

En octubre de 2017 se publica el informe sobre "El diseño y operación de mecanismos para la recaudación efectiva del IVA en casos donde el proveedor no se en- cuentra en la jurisdicción de impuestos", el cual señala las reglas y mecanismos para la recaudación efectiva del IVA sobre suministros transfronterizos de servicios e intangibles, según lo recomendado en las Directrices internacionales del IVA y en el Informe final de 2015 sobre la Acción 1 BEPS «Abordar los desafíos fiscales de la economía digital» de la OCDE.

\section{La prestación de servicios como hecho generador del IVA}

Para el nacimiento de cualquier obligación tributaria sustancial, es necesaria la realización del hecho generador. Este hecho, como lo expresa Marín (2015a), "es una creación del legislador, que a partir de un elemento de la realidad (el objeto o materia del tributo) configura una situación más compleja cuya realización lleva aparejada el nacimiento de la obligación tributaria" (p. 327).

\section{A. Elemento objetivo}

\section{Aspecto material}

A través del Decreto Ley 3541 de 1983, se produjo la inclusión de la prestación de servicios $^{7}$ como aspecto material, al disponer en el literal b) del Artículo 1 que "El impuesto a las ventas se aplicará sobre: b) la prestación de los servicios especificados en el Capítulo XVIII del presente Decreto, realizados en el territorio del país".

\footnotetext{
${ }^{7}$ Sobre el concepto de servicio, el Decreto 1372 de 1992 define, para efectos del IVA, que: “... se considera servicio toda actividad, labor o trabajo prestado por una persona natural o jurídica, o por una sociedad de hecho, sin relación laboral con quien contrata la ejecución, que se concreta en una obligación de hacer, sin importar que en la misma predomine el factor material o intelectual, y que genera una contraprestación en dinero o en especie, independientemente de su denominación o forma de remuneración".
} 
Posteriormente, el Artículo 25 de la Ley 6 de 1992 modifica el literal b) del Artículo 420 del ET para pasar de un régimen de gravamen selectivo a un régimen de gravamen general sobre los servicios, a excepción de los expresamente exonerados, definiendo una clasificación para los servicios en gravados, excluidos y exentos, y modificando el literal, así: b) La prestación de servicios en el territorio nacional.

Con la reforma tributaria estructural a través de la Ley 1819 de 2016, se modifica el hecho generador contenido en el literal b), y no solo grava los servicios prestados en el territorio nacional, sino también los prestados desde el exterior, siendo objeto de imposición del IVA toda prestación de servicios cuando el destinatario y usuario del servicio se encuentre localizado en el territorio nacional, con algunas excepciones, quedando así la modificación:

\section{Artículo 420. HECHOS SOBRE LOS QUE} RECAE EL IMPUESTO. El impuesto a las ventas se aplicará sobre: (...) c) La prestación de servicios en el territorio nacional, o desde el exterior, con excepción de los expresamente excluidos (destacado fuera del original).

\section{Aspecto espacial}

Para mayor comprensión de este aspecto, es preciso señalar lo establecido en el Código Civil, Artículo 18: "La Ley es obligatoria tanto a los nacionales como a los extranjeros residentes en Colombia", considerado por la Corte Constitucional como "el principio de la territorialidad de las leyes, conforme al cual estas solo obligan dentro del territorio del respectivo Estado" (Sentencia C-527 de 2003).
Para la Corte Constitucional (Sala Plena, Sentencia C-1157 de 2000), "el principio de la territorialidad de la ley es consustancial con la soberanía que ejercen los Estados dentro de su territorio; de este modo cada Estado puede expedir normas y hacerlas aplicar dentro de los confines de su territorio". Así mismo, sobre la territorialidad se ha expresado la Corte Constitucional en Sentencia C-1189 de 2000, al indicar que forman parte integral de este principio las reglas de "territorialidad subjetiva" (según la cual el Estado puede asumir jurisdicción sobre actos que se iniciaron en su territorio, pero culminaron en el de otro Estado) y "territorialidad objetiva" (en virtud de la cual cada Estado puede aplicar sus normas a actos que se iniciaron por fuera de su territorio, pero culminaron o tuvieron efectos sustanciales y directos dentro de él). (...) se puede considerar al principio de territorialidad como la regla general a aplicar, y a los demás principios como sus excepciones, puesto que legitiman el ejercicio extraterritorial de la jurisdicción.

Así las cosas, como lo establece el literal c del Artículo 481 del ET, la exportación de servicios se encuentra exenta de IVA, siempre y cuando: (i) los servicios sean prestados en el país; (ii) se utilicen exclusivamente en el exterior, y (iii) quienes utilicen el servicio sean empresas o personas sin negocios o actividades en Colombia. Contrario ocurre con los servicios prestados en el territorio colombiano y los prestados desde el exterior.

Como lo señalábamos en la descripción del aspecto material, cuando se produjo la inclusión de la prestación de servicios como hecho generador del IVA, solo estaban contemplados los realizados en el territorio del país, pero posteriormente, con el Artículo 25 
de Ley 6 de 1992, se modifica por los prestados en "el territorio nacional".

En el año 1995, con la Ley 223, se incorpora un parágrafo al Artículo 420 del ET, el cual modifica la regla de territorialidad, pero solo para los servicios de telecomunicaciones prestados mediante el sistema de conversión intencional del tráfico saliente en entrante, para considerarse prestados en "la sede del beneficiario".

Dos años más tarde, la Ley 383 de 1997 , en su Artículo 33, hace una modificación significativa al Artículo 420 del ET, al incorporar reglas de territorialidad mediante la adición del parágrafo 3 , señalando que los servicios se consideraran "prestados en la sede del prestador del servicio”, salvo algunas excepciones.

Este parágrafo 3 es modificado en su numeral 3, literales a), con adición del literal g), mediante la Ley 488 de 1998, precisando que la excepción a la regla general no es para los servicios prestados en la sede del destinatario o beneficiario, sino que la excepción a la territorialidad es para los servicios ejecutados desde el exterior a favor de usuarios o destinatarios ubicados en el territorio nacional, constituyéndose estos servicios en hecho generador del IVA:

\section{Artículo 420 del ET}

Parágrafo $3^{\circ}$. Para la prestación de servicios en el territorio nacional se aplicarán las siguientes reglas: Los servicios se considerarán prestados en la sede del prestador del servicio, salvo en los siguientes eventos: (...)

3. Los siguientes servicios ejecutados desde el exterior a favor de usuarios o destinata- rios ubicados en el territorio nacional, se entienden prestados en Colombia, y por consiguiente causan el impuesto sobre las ventas según las reglas generales: (...) (destacado fuera del original).

La territorialidad en este aspecto es modificada con la reforma tributaria estructural, Ley 1819 de 2016, con un cambio transcendental a las excepciones que contenía el Artículo 420 del ET para los servicios prestados desde el exterior, al modificar totalmente el parágrafo 3, numeral 3 e introducir la aplicación del principio de destino en las prestaciones de servicios desde el exterior, siendo objeto de imposición del IVA toda prestación de servicios cuando el destinatario y el usuario del servicio se encuentre localizado en el territorio nacional; con las excepciones contenidas en el parágrafo 4.

La aplicación del principio de destino en los servicios, como fue justificado en la exposición de motivos de la ley en comento por el Ministerio de Hacienda y Crédito Público (2016), (...) es una adecuación de la norma fiscal a nuevos fenómenos que se encontraban ajenos a la imposición del Impuesto, entre otros, a aquellos asociados al fenómeno de la economía digital que implica el reconocimiento de los avances de las TIC (tecnologías de la información y la comunicación) que han generado nuevas formas de prestaciones de servicios y generaciones de valor (p. 120).

Tenemos entonces que el literal c) del Artículo 420 del ET dispone que el impuesto a las ventas se aplicará sobre: c) La prestación de servicios en el territorio nacional, o desde el exterior, con excepción de los expresamente excluidos. 
Este artículo precisa en el parágrafo 3 que, para efectos del impuesto sobre las ventas, los servicios prestados y los intangibles adquiridos o licenciados desde el exterior se entenderán prestados, licenciados o adquiridos en el territorio nacional y causarán el respectivo impuesto cuando el usuario directo o destinatario de los mismos tenga su residencia fiscal, domicilio, establecimiento permanente, o la sede de su actividad económica en el territorio nacional.

Para la Corte Constitucional (Sentencia C-527 de 2003), gravar la prestación de servicios en el exterior a favor de usuarios ubicados en el territorio nacional en nada contraría la Constitución, porque se está ante la expresión de la potestad de configuración legislativa en la especificación del principio de territorialidad de la ley tributaria.

\section{Aspecto temporal}

Este aspecto que precisa el momento de causación del impuesto se refiere al momento en que se realiza el hecho generador, con lo cual se delimita el alcance de la obligación tributaria en el tiempo, pues es innegable el influjo que el tiempo proyecta en el nacimiento de la misma, así como en la exigibilidad por parte del sujeto activo (Marín, 2015c, p. 330).

En relación con el tiempo, señala Sainz de Bujanda que (citado en Marín, 2015d) (...) debe ser considerado al analizar cada uno de los problemas que el presupuesto plantea $\mathrm{y}$, particularmente, los siguientes: 1. la estructura temporal del hecho imponible; 2. el momento de nacimiento de la obligación tributaria; 3. el momento de exigibilidad de la prestación tributaria, y 4. la ley aplicable para la determinación del origen de la obligación (p. 330).

El Impuesto sobre las ventas es de causación instantánea; se genera el impuesto cada vez que se realiza uno de los hechos generadores. Como regla general, en las prestaciones de servicios, el momento de la causación del impuesto, según lo establece el literal c) del Artículo 429 del ET es en la fecha de emisión de la factura o documento equivalente, o en la fecha de terminación de los servicios o del pago o abono en cuenta, la que fuere anterior, aunque esta regla tiene excepciones que son consagradas en los Artículos 430 a 436 del ET (en el transporte aéreo o marítimo, servicio telefónico, seguros, seguros de transporte y seguros autorizados en moneda extranjera).

\section{Aspecto cuantitativo}

Este aspecto hace referencia al valor de la obligación tributaria que se concreta en la base imponible y sobre la que se aplica la tarifa correspondiente. La base viene a ser la expresión cifrada del presupuesto según lo indica Giannini (citado por Marín, 2015e).

El IVA es un impuesto de naturaleza real por cuanto afecta o recae sobre bienes y servicios, sin consideración alguna a la calidad de las personas que intervienen en la operación, de causación instantánea y de régimen de gravamen general, conforme con el cual la regla general es la causación del impuesto y la excepción la constituyen las exclusiones expresamente contempladas en la Ley (DIAN, Capítulo I, 1.5 Concepto Unificado IVA, 2003).

Como regla general, el Artículo 447 del E.T. define que la base gravable en la venta 
y prestación de servicios será el valor total de la operación, sea que esta se realice de contado o a crédito, incluyendo entre otros los gastos directos de financiación ordinaria, extraordinaria o moratoria, accesorios, acarreos, instalaciones, seguros, comisiones, garantías y demás erogaciones complementarias, aunque se facturen o convengan por separado $\mathrm{y}$, aunque considerados independientemente, no se encuentren sometidos a imposición; precisando la exclusión de los intereses por la financiación del IVA de la base gravable.

En cuanto a la tarifa, el Artículo 468 del ET la establece en diecinueve por ciento (19\%), salvo excepciones.

\section{B. Elemento subjetivo}

El elemento subjetivo hace referencia a los responsables del impuesto poseedores de derechos y obligaciones.

$\mathrm{Al}$ referirse a los sujetos pasivos, el ET, en el Artículo $2^{\circ}$, define como contribuyentes o responsables directos del pago del tributo a los sujetos respecto de quienes se realiza el hecho generador de la obligación sustancial; en el Artículo 792, igual precisión hace frente a la responsabilidad en el pago del impuesto, y en el Artículo $4^{\circ}$ aclara que para efectos del IVA se consideran sinónimos los términos contribuyente y responsable, así mismo los dos términos son equivalentes para la aplicación de las normas de procedimiento tributario, según lo establece el Artículo 558.

Sobre los responsables del IVA, la DIAN se ha pronunciado en el Concepto Unificado de IVA 001 del 2003, Título IX, Capítulo II, numeral 1:
El Impuesto sobre las ventas desde el punto de vista de la doctrina clásica es un impuesto indirecto, ya que existe un sujeto pasivo de iure y un sujeto pasivo de facto. Así, el primero es quien tiene la obligación de recaudar el impuesto, mientras que el segundo es quien efectivamente soporta las consecuencias económicas del mismo.

De este modo, quien soporta o asume la carga del tributo no es quien lo paga directamente a la entidad que administra los impuestos. La realización de cada acto gravado determina el recaudo. Una vez se verifique cualquiera de los supuestos de hecho generadores del tributo, el gravamen se causa y tiene el carácter de responsable del impuesto quien preste los servicios o venda bienes corporales muebles y el importador.

En consecuencia, el responsable del Impuesto sobre las Ventas es el sujeto a quien la ley le ha otorgado la facultad de recaudar (cobrar) el impuesto del consumidor final, en virtud de lo cual debe responder frente a la administración por su consignación y cumplir con las demás obligaciones inherentes a su calidad.

Sobre los responsables del impuesto sobre las ventas, el Artículo 437 del ET define que "Los comerciantes y quienes realicen actos similares a los de ellos y los importadores son sujetos pasivos" y señala en el literal b) que quienes presten servicios son responsables del impuesto.

$\mathrm{Al}$ analizar las modificaciones introducidas por la Ley 1819 de 2016 frente al elemento subjetivo, los proveedores del exterior son sujetos pasivos del IVA. Es así como el Artículo 178 de esta ley adicionó un pará- 
grafo al Artículo 437 del Estatuto Tributario (Responsables del impuesto sobre las ventas), en el siguiente sentido:

Parágrafo $2^{\circ}$. La Dirección de Impuestos y Aduanas Nacionales establecerá mediante resolución el procedimiento mediante el cual los prestadores de servicios desde el exterior cumplirán con sus obligaciones, entre ellas la de declarar y pagar, en su calidad de responsables cuando los servicios prestados se encuentren gravados.

La obligación aquí prevista solamente se hará exigible a partir del $1^{\circ}$ de julio de 2018 , salvo en aquellos casos previstos en el numeral 3 del artículo 437-2 de este estatuto (destacado fuera del original).

Por los problemas de territorialidad que plantea la importación de servicios gravados, el legislador estableció que i) si el adquirente de los servicios (incluidos todos) es del régimen común, este retiene el $100 \%$ del IVA según el Artículo 437.1 y numeral $3^{\circ}$ Art. 437-2 del ET; ii) si el adquirente no es del régimen común y tratándose de los servicios del Numeral $8^{\circ}$ del Artículo 437-2 el recaudo se hace por medio de los prestadores de los servicios que están en el exterior y si los proveedores no cumplen, los medios de pago harán la retención, exigencia que comienza a regir a partir de julio de 2018, y iii) en los demás casos, la DIAN ha manifestado que es el proveedor del servicio el responsable (DIAN, Concepto 013706, 2017).

\section{Tratamiento del IVA en la prestación de servicios transfronterizos, en el Derecho comparado}

Como el propósito de la investigación es proponer mecanismos eficientes para el recaudo del IVA que opera bajo el principio de destino en los servicios prestados desde el exterior a que se refiere el numeral $8 \mathrm{del}$ Artículo 437-2 del ET, esto es, los servicios electrónicos o los denominados servicios digitales (servicios audiovisuales, de plataforma de distribución digital de aplicaciones móviles, de publicidad online y suministro de enseñanza o entrenamiento a distancia, con las exclusiones previstas en los numerales 23, 24 y 25 del Artículo 476 del ET), se efectuará un análisis de la normativa aplicable al IVA en diferentes países, a fin de hacer un comparativo con relación a las medidas implementadas en Colombia, principalmente en la forma como han hecho frente a los grandes desafíos que impone la tributación atendiendo la ubicación del cliente.

Para los países con los que se va a realizar el comparativo de normatividad, la definición de servicios no tiene las mismas orientaciones, en el entendido de que existen la definición residual y la definición positiva complementada con una relación enunciativa de servicios gravados con el impuesto.

En los casos de Argentina y Colombia, adoptan en sus legislaciones la definición positiva de los servicios con una ilustración clara de las operaciones que los constituyen, mientras que países como España y, en general, por la Unión Europea, han adoptado la postura negativa o residual de los servicios, según la cual estos se definen como toda operación que no constituye entrega de bienes. Por ejemplo, en España, se recoge claramente la definición negativa de servicios, así: «Se entenderá por prestación de servicios toda operación sujeta al citado tributo que, de acuerdo con esta Ley, no tenga la consideración de entrega, 
adquisición intracomunitaria o importación de bienes», y complementa esta definición con una relación enunciativa de servicios gravados con el IVA (Villanueva, 2014).

En Colombia, encontramos la definición de servicios en el Decreto 1625 de 2016 en los siguientes términos: (...) se considera servicio toda actividad, labor o trabajo prestado por una persona natural o jurídica, o por una sociedad de hecho, sin relación laboral con quien contrata la ejecución, que se concreta en una obligación de hacer, sin importar que en la misma predomine el factor material o intelectual, y que genera una contraprestación en dinero o en especie, independientemente de su denominación o forma de remuneración.

\section{A. Argentina}

La ley del IVA en este país considera entre los hechos imponibles de este gravamen las importaciones de bienes y la importación de servicios al gravar determinadas prestaciones realizadas en el exterior cuya utilización o explotación efectiva se lleve a cabo en el país (Ley No.23349, 1986).

Dentro de los hechos imponibles del IVA definido en el Artículo 1 de la ley antes mencionada, el literal d) incorpora las prestaciones comprendidas en el inciso e) del Artículo $3^{\circ}$, realizadas en el exterior cuya utilización o explotación efectiva se lleve a cabo en el país, cuando los prestatarios sean sujetos del impuesto por otros hechos imponibles y revistan la calidad de responsables inscriptos ${ }^{8}$.

Los sujetos pasivos los define la ley como "los prestatarios" de tales servicios, destacando que el hecho imponible no se configura cuando el prestatario tenga frente al IVA otro carácter que no sea el de responsable inscripto ${ }^{10}$. El método para identificar el lugar de aplicación de tributación es el Principio de destino.

A diferencia de la legislación colombiana, la norma argentina no impone responsabilidad a los prestadores de servicios del exterior y limita el hecho generador del impuesto,

\footnotetext{
${ }^{8}$ Es importante aclarar sobre el tratamiento que Argentina les da a los servicios digitales: En el Artículo 3 de la ley del IVA, precisa: "Se encuentran alcanzados por el impuesto de esta ley las obras, las locaciones y las prestaciones de servicios que se indican a continuación: (...) y en su literal e) específica a "Las locaciones y prestaciones de servicios (...), en cuanto no estuvieran incluidas en los incisos precedentes: (...), dentro de estos enuncia en el numeral 21. m) Los servicios digitales. Se consideran servicios digitales, cualquiera sea el dispositivo utilizado para su descarga, visualización o utilización, aquellos llevados a cabo a través de la red Internet o de cualquier adaptación o aplicación de los protocolos, plataformas o de la tecnología utilizada por Internet u otra red a través de la que se presten servicios equivalentes que, por su naturaleza, estén básicamente automatizados y requieran una intervención humana mínima, comprendiendo, entre otros, los siguientes (...).

${ }^{9} \mathrm{cfr}$. Artículo $4^{\mathrm{o}}$, inciso g de la ley.

${ }^{10}$ Los responsables inscriptos deben percibir el débito fiscal e ingresarlo mensualmente, neto del crédito fiscal que corresponda de acuerdo con las disposiciones legales vigentes. La clase de factura que deberá emitir dependerá de la condición del comprador, locatario o prestatario, y será: Tipo A, cuando se trate de responsable inscripto o no inscripto en el IVA; Tipo B, cuando se trate de consumidores finales, sujetos exentos, no responsables o responsables del monotributo.
} 
solo cuando el cliente tenga la calidad de sujeto del impuesto y asuma la calidad de responsables inscriptos.

\section{B.Unión Europea (UE)}

La UE como comunidad política de derecho, no tiene un papel directo en el establecimiento y cobro de impuestos; sus decisiones fiscales requieren la unanimidad de todos los Estados miembros, garantizando de ese modo que se tengan en cuenta los intereses de cada país y cada uno de ellos es el que decide la cantidad de impuestos que pagan sus contribuyentes.

De tal manera, la fiscalidad indirecta está armonizada y coordinada a través de actos legislativos; se cuenta con un sistema común del Impuesto sobre el Valor Añadido ${ }^{11}$, cuya norma fundamental se encuentra contenida en la Directiva ${ }^{12} 2006 / 112 / \mathrm{CE}^{13} \mathrm{del}$ Consejo, modificado principalmente por la Directiva 2008/08/CE de este mismo organismo y en lo que tiene que ver con el lugar de la prestación de servicios está orientada a la modernización y simplificación del funcionamiento del régimen común del IVA, acuerda que el lugar de imposición debe ser, en principio, aquel donde se realiza efectivamente el consumo.

Tratándose de la prestación de servicios a sujetos pasivos, el servicio se entiende realizado en el lugar en que esté establecido el destinatario del mismo; mientras que, si estos se prestan a personas que no tienen la condición de sujeto pasivo, se entiende realizado en el lugar en el que el proveedor tiene establecida la sede de su actividad económica. Cuando un sujeto pasivo recibe servicios de un proveedor no establecido en el mismo Estado miembro, este sujeto debe efectuar la autoliquidación de la cuota del IVA repercutida por el servicio adquirido.

Son considerados "sujetos pasivos" quienes realicen con carácter independiente, y cualquiera que sea el lugar de realización, alguna actividad económica ${ }^{14}$, cualesquiera que sean los fines o los resultados de esa actividad.

\footnotetext{
${ }^{11}$ Según el Artículo 1, apartado 2 de la Directiva 2006/112/CE, El “principio del sistema común de IVA consiste en aplicar al comercio de bienes y servicios un impuesto general sobre el consumo exactamente proporcional al precio de los bienes y de los servicios, sea cual fuere el número de operaciones que se produzcan en el circuito de producción y distribución precedente a la fase de gravamen" (destacado fuera del original).

${ }^{12}$ Las directivas son actos legislativos en los cuales se establecen objetivos que todos los países de la UE deben cumplir. Sin embargo, corresponde a cada país elaborar sus propias leyes sobre cómo alcanzar esos objetivos. Definición tomada de la página de internet: https://europa.eu/europeanunion/eu-law/legal-acts_es.

${ }^{13}$ Esta Directiva se centra en la armonización de las normativas internas de los países miembros de la UE y establece una estructura común de IVA, una base imponible uniforme y unos tipos mínimos que determinarán los países de la UE.

${ }^{14}$ Como actividades económicas se entiende según la Directiva 2006/112/CE, "todas las actividades de fabricación, comercio o prestación de servicios, incluidas las actividades extractivas, las agrícolas y el ejercicio de profesiones liberales o asimiladas. En particular (...), la explotación de un bien corporal o incorporal con el fin de obtener ingresos continuados en el tiempo".
}

Revista de Derecho Fiscal n. ${ }^{\circ} 13$ • julio-diciembre de 2018 • pp. 91-127 
Los operadores establecidos en un tercer país ${ }^{15}$ solo están obligados a registrarse para efectos del IVA si su actividad incluye la venta a consumidores finales. Si el cliente es una empresa establecida en la UE, no están sujetos a obligación de ninguna clase, ya que las propias empresas clientes están sujetas al IVA sobre la base del principio de repercusión.

Así mismo, instaura el servicio de ventanilla única que opera a través de un sistema simplificado de tributación en línea, cuyo propósito es facilitarles a los proveedores no ubicados el registro de su identificación fiscal en un único Estado miembro de su elección. El tipo impositivo a aplicar depende del país de residencia del comprador.

\section{C.Japón}

En octubre de 2015 entró en vigor la ley de IVA digital en el país nipón. El límite anual para cobrar dicho impuesto es de 10.000.000 JPY (aprox. 86.400 EUR). El tipo impositivo es del 8\% (a partir del 1 de octubre de 2019 la tasa se incrementará al 10\%) y debe aplicarse en todas las ventas de productos digitales a particulares japoneses (Quaderno, 2018).

Los vendedores extranjeros deben registrarse previamente en la agencia tributaria japonesa. En las transacciones B2B, el comprador es el que tiene que aplicar el impuesto en su contabilidad. Al igual que en otros países, la definición de productos o servicios digitales es bastante amplia.

\section{Corea del Sur}

Considerado uno de los países tecnológicamente más avanzados del mundo. Aproximadamente un $90 \%$ de su población posee un teléfono inteligente y el consumo de productos digitales es muy alto; por lo que no es sorpresa que este país sea también uno de los pioneros en el establecimiento de este nuevo tipo de impuestos digitales. El tipo impositivo es del 8\%; al igual que en la UE, no existe límite anual para cobrar dicho impuesto, se aplica desde el primer momento en que se vende un producto o servicio digital a un residente surcoreano. Los impuestos recaudados deben pagarse trimestralmente en una cuenta del Woori Bank de la agencia tributaria coreana, y el impuesto debe abonarse en wones surcoreanos (Quaderno, 2018).

\section{E. Derecho comunitario - Comunidad Andina de Naciones (CAN)}

Colombia, como país miembro de la CAN, debe adoptar las medidas legislativas, reglamentarias y administrativas necesarias para el cumplimiento de los compromisos contenidos en las Decisiones que este organismo emita, como es el caso de la Decisión 599 de $2004^{16}$, que regula los aspectos sustanciales y los procedimientos de los impuestos tipo

${ }^{15}$ Se debe entender por «países terceros» todo Estado o territorio al que no se aplique el Tratado de la UE.

${ }^{16}$ Esta Decisión entró en vigencia a partir del $1^{\circ}$ de enero de 2008 , de acuerdo con lo previsto en la Decisión 635, del 19 de julio de 2006. 
valor que deben armonizarse en el régimen tributario interno.

Según la Decisión en comento, en el aspecto material del hecho generador, entre otros, el IVA se genera "en la prestación o utilización de servicios en el territorio nacional, acorde con el Artículo 12. Por su parte, las reglas para la territorialidad cuando los servicios trasciendan las fronteras, acoge varios criterios: 1) Se entenderán prestados o utilizados en el lugar donde se realicen materialmente, los siguientes servicios: a) Carga y descarga, trasbordo, cabotaje y almacenamiento de bienes; b) Los de carácter artístico, deportivo y cultural; 2) Los servicios que se presten desde el exterior y se utilicen o aprovechen por residentes o domiciliados en un País Miembro, se considerarán prestados en la jurisdicción de este país; tales como los que se mencionan a continuación $(. . .)^{17}$ y 3 ) Los servicios realizados sobre bienes inmuebles, se entenderán prestados en el lugar de ubicación de los mismos" (destacado fuera del original).

De acuerdo con la regulación colombiana, armoniza con las reglas de territorialidad del Artículo 12, numeral 2 de la Decisión 599, advirtiendo sobre el contenido del Artículo 24 de la Decisión 599, que determina el principio de imposición de servicios: en todos los países andinos regirá el principio de "imposición en el país de destino", salvo lo dispuesto en el Artículo 13.

Así mismo, precisa la Decisión de la CAN que el usuario o destinatario del servicio tendrá la condición de sujeto pasivo, cuando se trata de servicios gravados, prestados por no residentes ni domiciliados en el país donde se utilice el servicio, coincidiendo con lo estipulado en la normativa colombiana, cuando se trata de responsables del régimen común.

\section{Aplicación del principio de destino en la prestación de servicios transnacionales en Colombia}

\section{A. Criterios de localización del cliente para la determinación de los hechos imponibles en el territorio nacional}

Para efectos de la causación del IVA respecto a los servicios prestados desde el exterior, la ley previó cuatro criterios para identificar el usuario directo o destinatario de los mismos, si estos se entienden prestados, licenciados o adquiridos en el territorio nacional, en razón de su residencia fiscal, domicilio, establecimiento permanente o la sede de su actividad económica en el territorio nacional.

Para mayor comprensión de estos criterios cuyo análisis es necesario a fin de determinar

\footnotetext{
${ }^{17}$ El Artículo 12 de la Decisión ibídem, en el numeral 2, relaciona de manera taxativa los siguientes servicios: “a) Las licencias y autorizaciones para el uso y explotación, a cualquier título, de bienes incorporales o intangibles; b) Los servicios profesionales de consultoría, asesoría y auditoría; c) Los arrendamientos de bienes corporales muebles que se utilicen en el territorio del País Miembro; d) Los servicios de traducción, corrección o composición de texto; e) Los servicios de seguros relacionados con bienes ubicados en el territorio del País Miembro; f) Los realizados sobre bienes corporales muebles que permanecen u operan en el territorio del País Miembro; g) Los servicios de conexión o acceso satelital, cualquiera que sea la ubicación del satélite; h) El servicio de televisión satelital o cable recibido en el País Miembro; i) Los servicios de telecomunicaciones".
} 
que el lugar de consumo fue en el territorio nacional, haremos una breve descripción de cada uno de ellos, teniendo en cuenta la normatividad disponible en materia tributaria, comercial y civil.

\section{Residencia fiscal}

En materia tributaria, el concepto de residencia es un elemento fundamental, tanto a nivel interno como internacional, ya que determina la sujeción a la soberanía fiscal de un Estado, con incidencia en la forma de tributar y en el cumplimiento de algunos deberes formales correlativos.

La doctrina de la DIAN ha expresado que, "Jurídicamente, en el contexto del régimen impositivo relativo al impuesto sobre la renta y complementarios, la noción de residente se predica de las personas naturales y el domicilio de la sociedad y sus asimiladas" (DIAN, Oficio 657, 2013).

Es así como el Artículo 10 del ET regula únicamente los aspectos relacionados con la residencia de personas naturales para efectos tributarios en Colombia, precisando que "Se consideran residentes en Colombia para efectos tributarios las personas naturales que cumplan con cualquiera de las siguientes condiciones (...)". De manera resumida, sería la permanencia física en Colombia ${ }^{18}$, la relación con el servicio exterior del Estado colombiano ${ }^{19} \mathrm{o}$ la nacionalidad colombiana.

Según el numeral 3 del Artículo 10 ibídem, se requiere, además, que la persona natural cumpla alguna de las siguientes condiciones:

a) Su cónyuge o compañero permanente no separado legalmente o los hijos dependientes menores de edad, tengan residencia fiscal en el país; o,b) El cincuenta por ciento (50\%) o más de sus ingresos sean de fuente nacional; o, c) El cincuenta por ciento (50\%) o más de sus bienes sean administrados en el país; $o$, d) El cincuenta por ciento (50\%) o más de sus activos se entiendan poseídos en el país: o, e) Habiendo sido requeridos por la Administración Tributaria para ello, no acrediten su condición de residentes en el exterior para efectos tributarios; o, f) Tengan residencia fiscal en una jurisdicción calificada por el Gobierno Nacional como paraíso fiscal.

Tratándose de sociedades, es esencial la condición de nacional o extranjera en cuanto que de esa condición depende el régimen impositivo aplicable en materia del impuesto sobre la renta y complementarios. El Artículo 12-1 de ET menciona que para efectos tributarios se consideran nacionales las sociedades y entidades que durante el respectivo año o periodo gravable tengan su sede efectiva de

\footnotetext{
${ }^{18}$ La persona nacional o extranjera debe permanecer continua o discontinuamente en el país por más de ciento ochenta y tres (183) días calendario incluyendo días de entrada y salida del país, durante un periodo cualquiera de trescientos sesenta y cinco (365) días calendario consecutivos ${ }^{19}$ El numeral 2 del Artículo 10 ibídem define que la persona debe "Encontrarse, por su relación con el servicio exterior del Estado colombiano o con personas que se encuentran en el servicio exterior del Estado colombiano, y en virtud de las convenciones de Viena sobre relaciones diplomáticas y consulares, exentos de tributación en el país en el que se encuentran en misión respecto de toda o parte de sus rentas y ganancias ocasionales durante el respectivo año o periodo gravable".
} 
administración ${ }^{20}$ en el territorio colombiano o que cumplan una de las siguientes condiciones: tener su domicilio principal en el territorio colombiano o haber sido constituidas en Colombia conforme a las leyes colombianas vigentes; en su defecto, son consideradas sociedades extranjeras.

Para los proveedores extranjeros, quienes deben verificar este requisito para poder establecer que el usuario o destinatario está ubicado en el territorio nacional, además de comprobar si es del régimen común o no y luego sí proceder a aplicar el impuesto, resulta una tarea difícil si la administración tributaria no les brinda las herramientas a través de un procedimiento que les permita hacer tales confirmaciones.

\section{Domicilio}

De acuerdo con la forma como fue redactado el parágrafo 3 del Art. 420 del ET, la disposición no distinguió si se trata del domicilio civil, fiscal o mercantil para determinar la ubicación en el territorio nacional del usuario directo o destinatario de los servicios; redacción que puede prestarse a diversas interpretaciones, tratándose de circunstancias que determinan si el servicio que se presta desde el exterior se encuentra gravado.

Para las personas físicas, según la norma civil (Art. 76 C.C.) el domicilio consiste en "la residencia acompañada, real o presuntivamente, del ánimo de permanecer en ella", y define en el Art. 78 el domicilio civil como el "lugar donde un individuo está de asiento, o donde ejerce habitualmente su profesión u oficio".

Por su parte, el Art. 579-1 del ET determina el domicilio fiscal como el "asiento principal de los negocios". Este domicilio puede ser fijado por la DiAn, mediante resolución motivada cuando establezca que el domicilio principal de los negocios de una persona jurídica se encuentra en lugar diferente del domicilio social.

En relación con el domicilio social de una persona jurídica, el Artículo 110 del Código de Comercio dispone los requisitos que deben cumplirse para la constitución de una sociedad en Colombia, indicando, entre ellos, que la sociedad comercial se constituirá por escritura pública en la que, según el numeral 3 del artículo, debe contener el domicilio de la sociedad y el de las distintas sucursales que se establezcan en el mismo acto de constitución.

Así mismo, el Decreto 2460 de 2013, por el cual se reglamenta el Registro Único Tributario (RUT), ha dispuesto en el Artículo 4 los elementos que lo integran, y dentro de estos se encuentra la "ubicación" que comprende el domicilio principal, números telefónicos y correo electrónico, donde la DIAN puede contactar oficialmente y para todos los efectos, al respectivo inscrito. El domicilio principal inscrito en el formulario

\footnotetext{
${ }^{20}$ De conformidad con el parágrafo 1 del mismo artículo, la sede efectiva de administración de una sociedad o entidad es el lugar en donde materialmente se toman las decisiones comerciales y de gestiones decisivas y necesarias para llevar a cabo las actividades de la sociedad o entidad como un todo.
} 
del Registro Único Tributario (RUT), será el informado por el obligado; en el caso de las personas jurídicas o asimiladas, dicha dirección deberá corresponder a la señalada en el documento de constitución vigente y/o documento registrado.

La DIAN (Concepto 28049, 2015) ha precisado que "(...) para efectos fiscales, en el caso de las personas jurídicas, el domicilio a tener en cuenta es el domicilio social, conforme las previsiones legales mencionadas".

Para el efecto, traemos a colación un extracto de la sentencia del Consejo de Estado (Sala de lo Contencioso Administrativo, Sección Cuarta, expediente 7688 de 1996) que ilustra sobre la importancia de precisar lo que se entiende por domicilio como criterio de identificación del usuario de la prestación de servicios:

A juicio de la Sala es evidente que establecido en la ley como domicilio el "asiento principal" de los negocios, tal previsión implica entender que respecto de un mismo contribuyente puedan darse diferentes circunstancias que permiten la atribución de domicilio, con el consiguiente aspecto relativo a su pluralidad, pues lo cierto es que la movilidad geográfica de las personas físicas, por razones profesionales o comerciales, etc., puede dar lugar a que tengan permanencia y habitualidad en diferentes lugares a lo largo del periodo, a cuyo efecto, en la determinación del domicilio principal juega papel decisivo el criterio que para su clasificación se adopte, esto es, que el asiento principal de los negocios, o centro de intereses económicos puede ser el lugar donde la persona tiene sus principales inversiones, o aquel desde el cual administra sus bienes, o el sitio en el cual tiene oficinas o establecimientos, o el lugar donde desarrolla su actividad profesional, $o$ aquel en el cual obtiene la mayor parte de sus rentas, ubica sus activos, etc., aspectos que no están determinados en la ley.

\section{Establecimiento permanente}

Si se interpreta de manera análoga con el concepto definido para el impuesto de renta, el Modelo de Convenio Tributario sobre la Renta y el Patrimonio de la OCDE (2017) ${ }^{21}$ dispone, en su Artículo 5, “(...) la expresión "establecimiento permanente" significa un lugar fijo de negocios mediante el cual una empresa realiza toda o parte de su actividad" (p. 31); precisando que el término "fijo"; significa que debe estar establecido en un lugar determinado y con cierto grado de permanencia. Este concepto comprende en especial las sedes de dirección, las sucursales, las oficinas, las fábricas, los talleres, las minas, los pozos, entre otros.

En la legislación interna, la definición de este concepto se encuentra alineada con el concepto del Modelo de la OCDE, cuando el Artículo 20-1 del ET expresa que se entiende por establecimiento permanente, un lugar fijo de negocios ubicado en el país a través del cual una empresa extranjera, ya sea sociedad o cualquier otra entidad extranjera, o persona natural sin residencia en Colombia, según el caso, realiza toda o parte de su actividad. Comprende, entre otros, las sucursales de sociedades extranjeras, las agencias, oficinas, fábricas, talleres, minas, canteras, pozos de

${ }^{21}$ Documento en inglés sin traducción oficial, la traducción es propia. 
petróleo y gas, o cualquier otro lugar de extracción o explotación de recursos naturales.

El término "lugar fijo" ha sido objeto de muchas observaciones por cuanto no es eficaz en un contexto virtual, donde las nuevas herramientas tecnológicas hacen cada vez más sencillo estructurar digitalmente todo un concepto de negocio o actividad comercial, con escasa necesidad en muchos casos de contar con una importante presencia física para realizar actividades comerciales en una determinada jurisdicción, aunado al creciente papel de los efectos de la red generado por las interacciones con el cliente, causan dudas acerca de si las normas que se sustentan en la presencia física siguen siendo adecuadas (OCDE, 2014).

Para efectos del IVA, la Directrices de la OCDE no se remiten al Artículo 5 del Modelo de Convenio Fiscal, sino que dan al término "establecimiento" la definición de un "lugar fijo de negocios con el nivel suficiente de infraestructuras en términos de personal, activos y sistemas que le permitan recibir y/o realizar prestaciones", bajo el entendido de que el simple registro no constituye un establecimiento para estos efectos ${ }^{22}$.

En la reglamentación que está pendiente de la Ley 1819 de 2016, sería prudente que la DIAN hiciera claridad sobre la definición de establecimiento permanente, de tal forma que se ajuste a la nueva realidad económica y virtual, y en relación con los demás criterios, al no existir jerarquización para la definición de la localización, puede ocurrir que a un sujeto le aplique en un país el criterio de lugar de constitución y en el otro país el de sede de su actividad económica.

\section{Sede de su actividad económica}

El sistema tributario no tiene la definición de este criterio para identificar si el cliente de un servicio se puede considerar localizado en el territorio nacional; conviene esperar la doctrina de la DIAN sobre el desarrollo de este concepto.

En nuestra opinión, este criterio podría estar relacionado con el lugar en el que un sujeto pasivo (usuario del servicio prestado desde el exterior) ejerce las funciones de administración central de la empresa y en el que se desarrolla la actividad principal y esencial de la entidad.

\section{B. Modificaciones introducidas por la Ley 1819 de 2016 a los Artículos 420, 437 y 437-2 del Estatuto Tributario Nacional}

Como se ha expuesto en acápites anteriores, la reforma tributaria estructural de 2016 modificó el hecho generador del IVA en su aspecto material, espacial y subjetivo, siendo uno de sus principales propósitos la

\footnotetext{
${ }^{22}$ Sobre el tema de establecimiento permanente, es importante anotar las conclusiones a las que llegó un Tribunal en Europa en la Sentencia de 17 de julio de 1997, ARO Lease BV, C-190/95: “... para que, apartándose del criterio prioritario de la sede, un establecimiento pueda considerarse válidamente como el lugar de la prestación de servicios de un sujeto pasivo, es preciso que tenga un grado suficiente de permanencia y una estructura apta, desde el punto de vista del equipo humano y técnico, para hacer posibles, de forma autónoma, las prestaciones de servicios de que se trate".
} 
adecuación de la norma fiscal a los nuevos fenómenos asociados a la economía digital.

\section{Hecho generador}

La modificación introducida por la Ley 1819 de 2016 al Artículo 420 del ET, establece que los servicios están gravados en Colombia, bien sea que se presten en el territorio nacional o desde el exterior, con excepción de los expresamente excluidos. Para los servicios prestados desde el exterior, la norma señaló que estos se entienden realizados en el territorio nacional cuando el usuario directo o destinario de los mismos tenga su residencia fiscal, domicilio, establecimiento permanente o la sede de su actividad económica en el territorio nacional.

\section{Responsables del impuesto}

Frente a la responsabilidad de los prestadores de servicios, debe entenderse que al estar gravados los servicios prestados desde el exterior, los prestadores de servicios extranjeros tendrían tal responsabilidad, aunque en ninguno de los artículos de la reforma tributaria 2016 se hizo tal precisión. No obstante, el legislador encomendó en la DIAN definir el procedimiento mediante el cual dichos sujetos cumplirán con sus obligaciones, entre ellas la de declarar y pagar, en su calidad de responsables, cuando los servicios prestados se encuentren gravados, como quedó contemplado en el Artículo 437, parágrafo del ET.

Surge la inquietud de si los proveedores del exterior son responsables del impuesto cuando se trata de servicios gravados diferentes a los señalados en el numeral 8 del Artículo 437-2 del ET (servicios electrónicos o digi- tales) y cuando los adquirientes no son responsables del régimen común; sin embargo, aún no se conocen reglamentaciones al respecto, pero la DIAN, mediante Oficio 013706 emitido en junio de 2017, precisó que una vez tengan lugar las reglamentaciones pertinentes, la prestación de servicios diferentes de los referidos en el numeral 8 del Artículo 437-2, supone para los prestadores de los mismos la responsabilidad por el impuesto sobre las ventas.

Conviene advertir que, para el tema central del presente trabajo, nos referiremos a los proveedores del exterior como responsables del impuesto, solo para los servicios indicados en el numeral 8 del Artículo 437 2 del ET (servicios electrónicos o digitales) cuando los adquirientes no son responsables del régimen común, en cuyo caso se plantea el problema a investigar sobre la eficacia en el recaudo al no tener la administración tributaria elementos jurídicos para obligar a estos sujetos con las responsabilidades como las que tendría un responsable ubicado en el territorio nacional.

\section{Agentes retenedores}

Para asegurar el recaudo del IVA generado en los servicios prestados desde el exterior, la ley modificó y adicionó responsabilidades para los agentes de retención en el IVA y, al respecto, la DIAN, mediante oficio 013706 de junio de 2017, expresó:

$\checkmark$ Como regla general, las personas del régimen común practicarán retención del $100 \%$ del IVA por los servicios prestados desde el exterior, indistintamente de los servicios de que se trate, es decir, 
quedan incluidos los señalados en el numeral 8 del Artículo 437-2 del ET.

$\checkmark$ Las entidades emisoras de tarjetas crédito y débito, los vendedores de tarjetas prepago, los recaudadores de efectivo a cargo de terceros, y los demás que designe la DIAN en el momento del correspondiente pago o abono en cuenta a los prestadores desde el exterior, practicarán retención de IVA solamente cuando: 1) se trate de los servicios electrónicos o digitales definidos en el numeral 8 del Artículo 437-2 del ET y 2) los prestadores de servicios del exterior (únicamente en relación con servicios electrónicos o digitales) incumplan en su calidad de responsables del impuesto, con la obligación de declarar y pagar el impuesto. La aplicación de este sistema rige a partir del 1 de julio de 2018.

Los servicios electrónicos o digitales que fueron definidos en los literales a) a d) del numeral 8 del Artículo 437-2, son los siguientes $^{23}$ : a) Suministro de servicios audiovisuales (entre otros, de música, videos, películas y juegos de cualquier tipo, así como la radiodifusión de cualquier tipo de evento); b) Servicio de plataforma de distribución digital de aplicaciones móviles; c) Suministro de servicios de publicidad online; y d) Suministro de enseñanza o entrenamiento a distancia.

\section{Reflexiones sobre la aplicación del IVA en la prestación de servicios transfronterizos}

\section{El principio de destino}

Con el convencimiento de que la modificación realizada por el legislador a través de la Ley 1819 de 2016, al introducir el "principio de destino" como regla general para la aplicación del IVA a los servicios transfronterizos, fue una decisión acertada ${ }^{24}$, en primera instancia porque se encuentra alineado con las recomendaciones de organismos internacionales como la OCDE, acogido ampliamente por la doctrina e implementado en varios países, y porque este enfoque alcanza la neutralidad en el comercio internacional en razón de que no se deriva desventaja alguna de la

\footnotetext{
${ }^{23}$ Es importante anotar que existen servicios digitales que se encuentran excluidos del impuesto. El Artículo 476 del ET los enunció en los numerales 23, 24 y 25, así: “23. Los servicios de educación virtual para el desarrollo de Contenidos Digitales, de acuerdo con la reglamentación expedida por el Ministerio TIC, prestados en Colombia o en el exterior; 24. Suministro de páginas web, servidores (hosting), computación en la nube (cloud computing) y mantenimiento a distancia de programas y equipos y 25. Adquisición de licencias de software para el desarrollo comercial de contenidos digitales, de acuerdo con la reglamentación expedida por el Ministerio TIC". Cfr. Concepto DIAN No. 017056 de agosto 25 de 2017 que contiene precisiones sobre los servicios excluidos de IVA del artículo 472 numerales 23 y 25.

${ }^{24}$ La opinión la sustentó en que desde el marco tributario de la conferencia de Ottawa de 1998, titulada "Un mundo sin fronteras - Identificación del potencial del comercio electrónico", se establece como principio extenso que la tributación debería hacerse en la jurisdicción donde se lleva a cabo el consumo. Así mismo, la OCDE, en el documento The Effective Collection of VAT/ GST. Where the Supplier is not located in the jurisdiction of taxation (Sin traducción oficial al español), expone que, de acuerdo con el amplio consenso internacional, las directrices adoptan el principio de destino como la regla básica para la aplicación del IVA al comercio internacional. Este principio es establecido en la directriz 3.1. como sigue: "Para los fines del impuesto sobre el consumo de los servicios e intangibles comercializados internacionalmente deberían ser gravados de acuerdo con las reglas de la jurisdicción de consumo" (destacado fuera de texto).
} 
adquisición a jurisdicciones de baja o nula tributación y la configuración de las exportaciones del país no distorsiona los tipos más elevados y/o múltiples de IVA.

Cabe señalar que aunque este enfoque centrado en la jurisdicción en la que reside o se halla establecido el cliente, ha tenido una aceptación generalizada para aplicar el IVA al comercio internacional, su implementación y en especial lo referente a los servicios digitales, plantea desafíos generalizados para los sistemas tributarios, en el diseño y puesta en práctica de mecanismos para el recaudo eficiente del impuesto, sobre todo cuando se involucra como responsable del impuesto a los prestadores de servicios desde el exterior.

Para dar desarrollo al tema central de esta tesis y a fin de anticipar algunas complejidades que puedan surgir en la reglamentación que aún está pendiente por expedir la autoridad fiscal, se hará un análisis de las incidencias de aplicación práctica que puedan derivarse de estos artículos modificados en el ET y que pueden afectar el recaudo efectivo del IVA. Posteriormente, se plantearán dos propuestas, cuyo objetivo no es más que servir de apoyo a la administración tributaria en sus esfuerzos por encontrar e implementar mecanismos eficaces para un efectivo recaudo y control.

Los planteamientos están basados principalmente en las recomendaciones emitidas por la OCDE en las Directrices Internacionales del IVA, el Plan de Acción 1 BEPS de cómo abordar los desafíos fiscales de la economía digital, el documento emitido sobre mecanismos para el efectivo recaudo del IVA y las condiciones del marco fiscal del comercio electrónico, por considerar que estas han surgido de la necesidad de articular medidas eficaces frente a los conflictos de tributación que ocasiona la nueva realidad de la economía digital, con importantes contribuciones en su desarrollo de los países miembros de la OCDE, jurisdicciones más allá de la OCDE y de la comunidad global de los negocios.

\section{Ubicación del lugar de consumo e identificación del cliente}

Sobre la ubicación del cliente o el destinatario de los servicios, debemos hacer varias acotaciones; la primera es cuando se trata de responsables del régimen común, pues no habría inconveniente en el recaudo del impuesto vía retención en la fuente, ya que las normas internas contemplan sanciones en caso de incumplimiento por parte de estos sujetos, al no practicar ni consignar el valor calculado.

La segunda, relacionada con la responsabilidad del proveedor del exterior de calcular, recaudar y pagar el impuesto, cuando el usuario o destinario de los servicios no sea un responsable del régimen común o se trate del suministro de cualquiera de los servicios digitales enunciados en el Artículo 4372, numeral 8. En este evento, si no existen mecanismos efectivos de identificación, el proveedor estaría a la merced de la manifestación o conducta del cliente, sobre su calidad de obligado o el régimen de tributación que le aplica.

La tercera es referida a los criterios de localización del cliente para la determinación de los hechos imponibles en el territorio nacional, como son la residencia fiscal, domicilio, establecimiento permanente, o la sede de su actividad económica en el territorio nacional, 
que al igual que lo expuesto en párrafo anterior, tendría responsabilidad el proveedor del exterior en obtener información si su cliente cumple cualquiera de esos criterios.

\section{Proveedor del exterior como responsable del impuesto}

Cuando el proveedor del servicio no se encuentra en Colombia, genera grandes retos para la administración tributaria al no tener autoridad con eficacia para hacer cumplir las obligaciones que estos sujetos adquieren como responsables del impuesto.

Surge entonces la pregunta de cómo se efectuará el recaudo del IVA en los servicios señalados en el numeral 8 del Artículo 437-2 del ET cuando el consumidor no sea del régimen común, si los proveedores del exterior, como responsables de efectuar el recaudo, lo hacen de forma voluntaria, y en caso de incumplimiento, como procedería la sanción. Como lo expresa Lamensch (2012), las administraciones tributarias competentes, en la práctica, no tendrían la posibilidad de realizar las debidas inspecciones y de sancionarlos ante su eventual incumplimiento.

Cabe recordar las obligaciones que a nivel interno tienen los responsables del IVA, pertenecientes al régimen común:

1. Inscribirse en el RUT e incluir la responsabilidad "ventas régimen común".

2. Solicitar ante la DIAN la resolución de autorización para facturar.

3. Expedir factura con el lleno de todos los requisitos.

4. Llevar contabilidad (con algunas excepciones, ejemplos, agricultores, ganaderos).
5. Facturar y cobrar el IVA.

6. Presentar declaración de IVA ante la DIAN y hacer el respectivo pago del impuesto.

7. Obligación de informar el cese de actividades.

$\mathrm{Al}$ analizar las anteriores obligaciones, surge una pregunta: ¿Está la DIAN preparada a través de su página web para responder a las necesidades de los proveedores para el cumplimiento de sus obligaciones como responsables del IVA? Si la respuesta fuese afirmativa, ¿estaría el proveedor del exterior dispuesto a cumplir con todas las obligaciones?

\section{Agentes de retención de IVA como mecanismo de recaudo}

Para que las entidades emisoras de tarjetas crédito y débito, los vendedores de tarjetas prepago, los recaudadores de efectivo a cargo de terceros y los demás que designe la DIAN en el momento del correspondiente pago o abono en cuenta practiquen la retención de IVA, se deben cumplir dos condiciones: la primera, que se trate del suministro de servicios electrónicos o digitales señalados en el literal 8 del Artículo 437-2 del ET y, la segunda, solo bajo la circunstancia de que el prestador del servicio desde el exterior, incumpla con sus obligaciones de declarar y pagar.

Esta medida podría resultar muy favorable para asegurar el recaudo del impuesto, si tenemos en cuenta que los consumidores hacen uso de este medio de pago en porcentajes elevados, así como lo informó la Cámara Colombiana de Comercio Electrónico (2016) para el primer semestre de 2017, “(...) evidenciamos que el medio de pago por excelencia utilizado por los consumidores online para la 
compra de bienes y/o servicios es la tarjeta de crédito, con una penetración del $92 \%$, frente al $8 \%$ del débito a cuenta bancaria".

No obstante, no es claro el procedimiento para que los agentes de retención verifiquen en tiempo real el cumplimiento del proveedor extranjero para proceder o no a practicar la retención en el momento del pago, a menos que si en la factura no está estipulado el impuesto, por defecto, procede la retención de IVA. Significaría retos muy grandes para la DIAN y para las entidades sujetos de retención, el diseñar un sistema de información que permita identificar sobre qué pagos ha de efectuarse la retención. Adicionalmente, sería un poco más complejo en la práctica cuando los pagos se realicen con tarjetas de crédito expedidas por bancos internacionales o se utilice otro medio de pago como los bitcoins.

Otro de los retos que deben asumir estos agentes de retención es identificar que el servicio que se está pagando obedece exactamente a los enunciados en los literales a) a d) del numeral 8 del Artículo 437-2 y que la factura contenga exclusivamente suministro de servicios gravados; de lo contrario, se distorsionaría la base gravable para aplicar la retención. Adicionalmente, verificar que el usuario o consumidor del servicio se encuentre ubicado en el territorio colombiano.
Así mismo, se tendría que regular otro aspecto relacionado con "las entidades emi$\operatorname{soras}^{25}$ " de tarjetas de crédito y débito, por cuanto estos bancos no tienen una relación contractual de adquirencia con el consumidor; son los bancos adquirentes ${ }^{26}$ con los cuales los establecimientos de comercio han celebrado previamente un contrato para recibir y compensar los saldos que reciban con ocasión de las ventas canceladas con medios de pago electrónicos.

No obstante, la DIAN está facultada para señalar mediante lista a qué prestadores desde el exterior se les debe aplicar la retención de IVA en el evento de incumplimiento de sus obligaciones. Por lo tanto, la reglamentación puede tener otro direccionamiento por el conocimiento que se tiene de los proveedores a quienes se les practica la retención.

\section{Propuestas sobre los Mecanismos que puede adoptar Colombia para el recaudo eficiente del IVA en los Servicios Transfronterizos}

En consideración a que la reforma tributaria precisó que la obligatoriedad de los proveedores del exterior como responsables del impuesto comienza a regir a partir del mes de julio de 2018, la primera propuesta está

\footnotetext{
${ }^{25}$ Habría que distinguir su significado; según el Decreto 2230 de 2006, en su Artículo $1^{\circ}$. Definiciones. a) Establecimientos de crédito emisores: son los establecimientos de crédito que, dentro de un sistema abierto de tarjetas, emiten tarjetas débito o crédito a favor de los tarjetahabientes; b) Establecimientos de crédito adquirentes: son los establecimientos de crédito que, dentro de un sistema abierto de tarjetas, pagan, a los propietarios de los establecimientos de comercio en los cuales los tarjetahabientes realizan adquisiciones con tarjetas débito o crédito, el valor de las utilizaciones efectuadas con tales tarjetas.

${ }^{26}$ Redacción apoyada en el documento de la Cámara Colombiana de Comercio Electrónico que fue enviado al senador Óscar Mauricio Lizcano Arango, Presidente del Congreso de la República, el 17 de noviembre de 2016, con ocasión de los Comentarios al Proyecto de Ley No. 178 de 2016 Cámara 163 de 2016 Senado "Por medio de la cual se adopta una reforma tributaria estructural, se fortalecen los mecanismos para la lucha contra la evasión y la elusión fiscal, y se dictan otras disposiciones".
} 
enfocada en la implementación de un régimen simplificado para el registro y recaudo del impuesto por parte de estos sujetos pasivos, desde la perspectiva de las directrices de la OCDE.

La segunda propuesta se motiva sobre la conclusión a la que se llega una vez planteado el régimen simplificado aplicable a los proveedores extranjeros, puesto que se trata de un régimen voluntario, donde el incumplimiento puede no traer consecuencias; lo que sugiere un riesgo para el recaudo del impuesto $y$ un apremio en buscar otras alternativas.

\section{Propuesta 1. Implementar un Régimen}

Simplificado de Registro y Recaudo para el proveedor del extranjero

La propuesta de adopción de esta medida se origina en una primera premisa que es la urgencia de la reglamentación de la ley, mientras llega el momento de adoptar medidas más ambiciosas a mediano plazo que faciliten el cumplimiento de las obligaciones fiscales respecto a los servicios transfronterizos, $\mathrm{y}$ una segunda, porque desde el año 2008 Colombia manifestó su voluntad de adherirse a la OCDE y está adelantando todas las acciones para cumplir con los estándares que allí se exigen. Por lo tanto, resulta pertinente seguir las Directrices Internacionales del IVA, en las que se exponen los mecanismos a implemen- tar cuando el proveedor se encuentra en otra jurisdicción a la del impuesto.

\section{i. Identidad del usuario o destinario de los servicios}

Sobre la responsabilidad del proveedor del exterior frente a la ubicación del cliente en Colombia, se proponen los siguientes aspectos que deberían ser objeto de una pertinente labor de implementación o guía para que los proveedores puedan comprobar que los servicios se consideran realizados en el territorio nacional, teniendo como principio la flexibilidad y facilidad para que se puedan aplicar:

$\checkmark$ La DIAN debe proporcionar información sobre los contribuyentes que se encuentran inscritos en el Registro Único Tributario (RUT), de tal forma que el proveedor pueda corroborar la situación del cliente, en especial el régimen de IVA al que pertenece.

$\checkmark$ Sugerir al proveedor la consulta a los links de entidades que pueden ofrecer información relevante para la identificación del cliente, entre otros, registro mercantil, Registraduría del Estado Civil.

$\checkmark$ Una opción viable es la implementación de certificados digitales o certificados de identidad ${ }^{27}$, los cuales pueden contener información sobre el estado del cliente y específicamente información sobre el registro del IVA.

\footnotetext{
${ }^{27}$ Para mayor comprensión, un certificado digital definido como una forma digital de identificación, como un pasaporte o el permiso de conducir, es una credencial digital que proporciona información acerca de la identidad de una entidad, así como otra información auxiliar. Los certificados digitales los emiten las autoridades competentes, denominadas entidades emisoras de certificados (CA). Como un certificado digital está emitido por una entidad emisora de certificados, dicha entidad garantiza la validez de la información contenida en el certificado. Además, un certificado digital solo es válido durante un período específico de tiempo. Disponible en página de internet: https:// technet.microsoft.com/es-co/library/bb123848(v=exchg.65).aspx
} 
$\checkmark$ En el evento de que el proveedor del exterior realice esfuerzos razonables por obtener la evidencia apropiada del cliente en relación con la calidad de sujeto del régimen común y, pese a sus esfuerzos no logre su objetivo, se debe reglamentar la presunción de buena fe para que el proveedor proceda como responsable del impuesto.

$\checkmark$ Para acreditar o comprobar el domicilio del cliente o la permanencia en el territorio nacional, en operaciones B2C, la DIAN debe valorar los esfuerzos que realice el proveedor del exterior, exonerándolos de cualquier responsabilidad en la medida en que haya actuado con una mínima diligencia, cuando por la conducta del cliente o por omisión dolosa se dé un trato inadecuado de las operaciones, contemplando como válidas las siguientes actuaciones del proveedor extranjero:

- Reconocer en principio la información proporcionada por el cliente como evidencia relevante para la determinación de la jurisdicción de la residencia habitual de este, haciendo prevalecer la neutralidad de las operaciones y la buena fe de las partes.

- La información del cliente valorado como confiable, recopilada con anterioridad, de la que como mínimo se tienen en cuenta dos elementos no contradictorios (facturas, contratos, direcciones, pedidos, entre otros).

- En caso de no contar con información confiable o no estar disponible o esta sea limitada, se le permita al proveedor las consultas al sector empresarial, de tal forma que pueda tener una buena aproximación del lugar de residencia habitual.

- El uso combinado de información; análisis comerciales validados con información tecnológica, como, por ejemplo, dirección de protocolo de Internet (IP), dirección de facturación, tarjetas de crédito.

- La observancia de las normas aplicables en Colombia y en la jurisdicción del proveedor, respecto a la protección de la privacidad personal.

- La norma debe prever una sanción para los usuarios o destinatarios de los servicios que suministren información falsa a los proveedores cuya finalidad sea la no aplicación del impuesto.

- El indicio basado en el valor del suministro; si, por ejemplo, se trata de un paquete de software, podría corresponder a una persona con negocios formales y no de un consumidor final.

La experiencia en la Unión Europea es que al proveedor le resulta extremadamente gravoso obtener en ciertas circunstancias dos elementos de prueba no contradictorios para identificar dónde se encuentra establecido el cliente, especialmente para pequeñas y medianas empresas.

\section{ii. Proveedor del exterior como responsable del impuesto}

No se puede desconocer que los proveedores extranjeros, cuando se enfrentan a un procedimiento complejo para el cumplimiento de sus obligaciones, pueden optar por el incumplimiento, la ilegalidad, el fraude, o por no realizar operaciones con personas ubicadas en el territorio colombiano, cuyo efecto puede ser un fuerte impacto en el recaudo del IVA y en el desarrollo del comercio electrónico. En Colombia, según el informe de rendición de cuentas de la DIAN (2017), el IVA interno representa el segundo lugar en términos de recaudo, con un aporte del $26 \%$ 
dentro de la composición de los ingresos que administra la DIAN.

Bajo tal premisa y como lo expresan las directrices internacionales de IVA, se debe facilitar y motivar a los proveedores del exterior al cumplimiento voluntario de las obligaciones como responsables del impuesto, en cuyo caso se propone adoptar un régimen simplificado de registro y recaudo que comprenda la información estrictamente necesaria para el efectivo recaudo del impuesto ${ }^{28}$, teniendo presente la coherencia que debe existir entre las cargas de cumplimiento y los ingresos por el recaudo, sin desconocer que su implementación es un gran reto.

Las siguientes son las consideraciones propuestas, con la advertencia de que el régimen simplificado debe operar solo en los eventos en que el proveedor extranjero no esté obligado a calcular y pagar el IVA en su país, es decir, solo para efectos de pago y no para solicitar algún tipo de devolución amparado en la legislación de su país:

\section{a) Proceso de inscripción}

Para el registro en línea del proveedor, se debe ubicar un "link de inscripción" en un lugar visible de la página web de la DIAN, acompañado de un instructivo que explique paso a paso qué debe realizar, así como ofrecer al usuario la traducción en varios idiomas. Los datos solicitados deben ser sencillos de diligenciar, por ejemplo: nombre y apellidos y/o razón social o estableci- miento comercial; dirección, teléfono, dirección electrónica y URL de sitios web de proveedores no residentes, con los cuales realiza negocios en la jurisdicción fiscal de su país; número de identificación fiscal asignado por su país; ciudad y país.

El aplicativo de inscripción debe permitir actualizar o corregir la información de registro en línea, acceder el ingreso de documentos soporte en caso de ser necesarios y, una vez realizadas las validaciones que la DIAN considere oportunas, asignar y notificar a través de medios electrónicos el número de NIT al sujeto pasivo extranjero, pudiendo acceder el prestador de servicios a partir de ese momento al menú de proveedores extranjeros registrados en la DIAN.

\section{b) Alternativa de establecer sustituto por parte de los proveedores extranjeros}

Una opción que puede evaluar la DIAN para facilitarles a los proveedores extranjeros el cumplimiento de las obligaciones impuestas es autorizar a los proveedores para que designen un proveedor de servicios especializados que actúen en su nombre para el cumplimiento de los deberes como sujeto responsable. Esta alternativa puede ser beneficiosa, en el estricto sentido de hacer reducir las cargas de cumplimiento y gastos administrativos a los proveedores.

\footnotetext{
${ }^{28}$ Las Directrices Internacionales del IVA caracterizan los regímenes simplificados de recaudación basada en el registro como "en la actualidad, el enfoque más eficaz y eficiente para garantizar la recaudación adecuada del IVA en los suministros transfronterizos entre empresas" (sin traducción oficial, la traducción es propia).
} 


\section{c) Definición de umbrales}

Es conveniente implementar un umbral para que por debajo del monto que se determine, los proveedores se exoneren de la obligación de registrarse, cobrar, declarar y consignar el IVA a Colombia. Este umbral se puede establecer con referencia al volumen de ventas realizadas en un año hacia Colombia y no por valor de operación, para así evitar que las transacciones sean fraccionadas.

Lo anterior apunta a minimizar el riesgo de incurrir en costos administrativos para el proveedor y para la misma DIAN, al liberarse de consumo de tiempo en auditar una cantidad de transacciones por cuantías menores que en un análisis costo-beneficio el resultado sería negativo para el recaudo.

A nivel interno del país, la norma contempla un umbral en la prestación de servicios, "Cuando la operación económica no supera los topes mínimos de $4 \mathrm{UVT}^{29}$...”, aproximadamente US $\$ 46^{30}$, aspecto importante por la posición competitiva de los proveedores nacionales y extranjeros.

\section{d) Procedimiento de facturación, decla- ración y pago del IVA cobrado por el proveedor extranjero}

Sobre la facturación, y en especial sobre los requisitos para su elaboración, la administración tributaria debe ser flexible y permitir como válida la emisión de la factura, atendiendo la normatividad de la jurisdicción del proveedor o, en su defecto, los requisitos deben ser los estrictamente necesarios para garantizar la verificación del cumplimiento de los proveedores. Esto significaría, además, aceptar que la factura se presente en distintos idiomas o, por lo menos, en los que manejan los principales socios comerciales.

La segunda gran obligación por la que han de responder los proveedores extranjeros es la relativa a la presentación de las declaraciones de IVA, con el consiguiente ingreso del impuesto calculado; al tiempo de presentar la declaración, deberán efectuar el pago de la deuda tributaria en la cuenta bancaria que se designe por parte de la DIAN.

Al igual que como está establecido para los responsables del impuesto ubicados en Colombia, y por razones obvias, la declaración debe ser vía electrónica. En relación con la periodicidad, la DIAN debe analizar la conveniencia de si es bimestral o por un periodo mayor, que podría estar relacionado con el volumen de impuesto que se recauda por los servicios electrónicos o digitales en las distintas jurisdicciones, con el diseño de un formulario sencillo y de fácil diligenciamiento, previendo la traducción en varios idiomas.

El pago del impuesto hacia Colombia vía electrónica no debe causar mayores costos para el proveedor del exterior $\mathrm{y}$,

\footnotetext{
${ }^{29}$ Para el año 2018, la DIAN fijó en \$33.156 la Unidad de Valor Tributario (UVT).

${ }^{30}$ Conversión hecha a la Tasa Representativa del Mercado de \$2.862,78.
} 
preferiblemente, el procedimiento debe contemplar el pago en otra moneda diferente al peso colombiano; la tarea de conversión la debería efectuar la DIAN, aunque las directrices de la OCDE recomiendan que el proveedor debe hacer la conversión a la moneda de la jurisdicción del impuesto, esta labor puede acarrear dificultad, lo que en principio se quiere evitar con este régimen.

Adicionalmente, existen otros aspectos a tener en cuenta para facilitar el pago, como: a) proporcionar orientación clara sobre los medios de pago aceptados; $b$ ) no exigir a los proveedores extranjeros apertura de cuentas bancarias en Colombia, y c) implementar protocolos de seguridad en la realización del pago y que éstos no sean objeto de posibles ataques cibernéticos.

En relación con el registro de datos, la DIAN debe orientar al proveedor, mediante procedimiento, sobre el almacenamiento y disposición de los registros electrónicos de las transacciones de suministros de servicios realizadas, de tal forma que la administración tributaria pueda tener acceso oportuno y en línea para verificar el cumplimiento del proveedor, asegurando la legibilidad de los datos, claves de acceso, periodos de almacenamiento de la información, entre otros factores y sustentados bajo el principio de la buena fe.

Si por alguna circunstancia el proveedor del extranjero requiere hacer alguna acción como corregir, solicitar el pago en exceso o de lo no debido, debe existir un procedimiento para este trámite, sin desconocer los protocolos de seguridad que adviertan que estas solicitudes no estén encaminadas a un fraude hacia el Estado colombiano.

Ante el incumplimiento del proveedor de registrarse en el RUT y cumplir las demás obligaciones oportunamente, el procedimiento debe considerar la facilidad para que lo haga de manera extemporánea y fomentando esquemas voluntarios de cumplimiento, sin llegar a fomentar el uso abusivo de estas disposiciones.

\section{iii. Administración tributaria}

La administración tributaria juega un papel muy importante en la implementación del régimen simplificado y debe asumir grandes retos para que, a través de estrategias de comunicación e información, logre el acercamiento voluntario y óptimos niveles de cumplimiento por parte de estos responsables ubicados fuera del territorio colombiano, lo que deriva en un recaudo eficiente y eficaz del impuesto.

Se debe ofrecer al proveedor extranjero a través de un canal web dedicado información que le permita comprender, entre otros aspectos, lo siguiente: proceso de registro, obligaciones de los responsables, bases de datos para verificar la calidad de los clientes, legislación y jurisprudencia del IVA, requisitos para solicitudes de devolución, traducción en varios idiomas, umbrales, mecanismos de recaudo aplicables, requisitos de facturación, tasas aplicables, plazos para declarar, procedimiento de correcciones y, en general, toda información que le facilite el correcto y oportuno cumplimiento de sus deberes. Además, disponer de un punto de contacto específico 
que pueda responder a las consultas de los sujetos responsables.

Por lo tanto, la DIAN debe continuar en su proceso de actualización tecnológica y de modernización de los procesos administrativos, en la medida en que el control de las operaciones transfronterizas exige reconsiderar los métodos de fiscalización in situ o con expedientes donde la documentación es lo esencial, hacia modelos en los que el auditado se encuentra en diferentes países y el auditor debe hacer su labor de manera remota, apoyado en los sistemas informáticos.

\section{Propuesta 2 - Desarrollar un sistema de integración a nivel comunitario a través de la CAN}

El auge del comercio electrónico ha generado para el Derecho tributario grandes desafíos en encontrar la fórmula para desarrollar un sistema fiscal que grave de manera eficiente, neutra y justa las transacciones digitales, particularmente en los impuestos indirectos; es por ello que nos encontramos en un marco tributario en el que todavía no existe un encaje claro ni en la normativa interna de los países ni en el plano internacional que intente disminuir los efectos fiscales que produce la nueva realidad económica digital, admitiendo que las soluciones a esta problemática no se pueden plantear desde un solo país, sino que deben abordarse a través de acuerdos ampliamente consensuados con diferentes estados.

El ideal sería encaminar los esfuerzos hacia la armonización del sistema tributario internacional, pero en el mediano plazo la posibilidad que se vislumbra es baja, en consideración a los intereses y disímiles puntos de vista de los Estados, mientras que las tran- sacciones transfronterizas siguen en auge y los participantes de estos mercados toman ventajas de las brechas existentes en el control y recaudo efectivo del IVA; por lo tanto, la propuesta va encaminada hacia un nivel comunitario.

En este sentido, se propone unir esfuerzos a través de la Comunidad Andina de Naciones (CAN), en línea con el propósito que persigue este organismo por su carácter multidimensional y el objetivo que se ha buscado con la Decisión 599 del 12 de julio de 2004 de armonizar los aspectos sustanciales y procedimentales del IVA entre los países miembros.

La primera tarea que se debe emprender es hacer realidad la armonización del IVA en los países miembros, a fin de obtener la neutralidad en la aplicación de dicho impuesto para que los resultados sean comparables en cuanto a hecho generador, tarifa, base gravable y obligaciones de los sujetos pasivos, además de lograr la eliminación de los obstáculos a la libre circulación en la prestación de servicios. Una vez logrado lo anterior, iniciar acciones relacionadas con el manejo de la tributación del IVA en los servicios transfronterizos.

Partiendo del precepto de que los países miembros aplican el principio de destino como base para aplicar el IVA al comercio internacional, se debe adoptar un régimen común a nivel comunitario en los Estados miembros, aplicable a los servicios electrónicos o digitales, así:

Si el proveedor que suministra servicios electrónicos o digitales se encuentra establecido en un estado miembro de la CAN, distinto al Estado donde está establecido el destinatario del servicio, el sujeto pasivo es 
el prestador del servicio, quien debe aplicar el IVA y responder ante el Estado miembro donde él se encuentra ubicado, declarando y consignando el impuesto recaudado.

$\checkmark$ Una vez recibido el impuesto por el Estado miembro donde se encuentra el proveedor, esta Administración Tributaria entregará el impuesto recaudado a la jurisdicción del destinatario del servicio a quien le corresponde el tributo.

A modo de ejemplo, si un proveedor de servicios digitales se encuentra ubicado en Colombia y el destinatario del servicio está ubicado en Bolivia, el proveedor de Colombia recauda el IVA y declara ante la Administración Tributaria de este país, además de responder por el pago del impuesto recaudado. Posteriormente, la Administración Tributaria de Colombia envía el IVA recaudado a Bolivia, país al que realmente le corresponde el tributo.

De esta forma, la Administración Tributaria de Bolivia no queda a la voluntad del proveedor de Colombia para que efectúe el recaudo y posteriormente declare y envíe el valor del impuesto a Bolivia. En Colombia, por el acuerdo comunitario, en caso de incumplimiento por parte del proveedor, este estaría expuesto a sanciones.

Con esta propuesta, se pretende llevar a los países miembros a idear un ordenamiento susceptible de evolucionar en línea con la economía digital, teniendo como principal ingrediente la cooperación entre las administraciones tributarias que, además de lograr un recaudo efectivo del impuesto, se encamine hacia la optimización de recursos administrativos de cumplimiento y fiscalización.
Adicionalmente, dada la dificultad de los proveedores para identificar si el cliente destinatario del servicio se encuentra establecido en uno de los países miembro, se propone diseñar una multiplataforma que contenga una estructura de datos global y como componente adicional que maneje información geográfica que permita ubicar el lugar donde se encuentra el destinatario o usuario del servicio.

Para plasmar esta idea en un escenario práctico, la multiplataforma se debe desarrollar a través de la creación de una IDE (Infraestructura de datos espaciales), que consiste es un sistema informático compuesto por un conjunto de recursos (catálogos, servidores, programas, aplicaciones, páginas web, etc.), armonizados bajo un marco legal que garantiza la interoperabilidad, de modo que se asegura que los datos producidos por las instituciones puedan ser compartidos por toda la administración (Bermejo, E y Conti, L., 2014).

Su objetivo es compartir la información geográfica en la red y ponerla a disposición de los usuarios. La información con la que se alimenta la IDE se tomará de las bases de datos de las administraciones de impuestos y de las Cámaras de Comercio de cada país, con el objeto de poder conocer, además de la ubicación de los consumidores de los servicios, información relevante como nombre, dirección, teléfono, ubicación, tipo de régimen aplicable en IVA, entre otros, y en general los datos mínimos requeridos para que el proveedor, una vez hecha la consulta, satisfaga sus dudas sobre la ubicación del cliente y en relación con la aplicación del impuesto pueda hacerlo de manera correcta. 
Para mayor transparencia en el manejo de la IDE, como mejor opción, se propone que sea la CAN el organismo rector de las políticas del manejo de información. Es importante tener en cuenta las normas que rigen el tema de la protección de datos en cada país, de tal forma que no sea un obstáculo para el avance de esta iniciativa propuesta y de ser necesario hacer las modificaciones a la normatividad a que haya lugar para tal fin.

\section{Conclusiones}

$\checkmark$ Así como fue reconocido en la Declaración Ministerial de la OCDE sobre Economía digital (2016), esta economía basada en la tecnología digital es un potente motor de la innovación, el crecimiento y la prosperidad social, que está transformando profundamente nuestra sociedad, derivado del uso de las tecnologías de la información y la comunicación. Este fenómeno de alcance mundial ha repercutido en varios ámbitos, uno de ellos es la fiscalidad y, por ende, hace necesaria la evolución de las normas tributarias hacia marcos de política tributaria transfronteriza compatibles con estas nuevas prácticas comerciales, retos que no han sido fáciles de afrontar.

$\checkmark$ Colombia no es ajena a este fenómeno de la Economía digital, y con la reforma tributaria estructural, Ley 1819 de 2016, ajusta la norma fiscal e introduce la aplicación del principio de destino en las prestaciones de servicios desde el exterior, decisión que consideramos acertada porque este criterio se encauza en gravar únicamente el consumo final en el territorio colombiano y desgravar lo ejecutado en el exterior; de acuerdo con el consenso internacional. Esta es una regla básica para la aplicación del IVA al comercio internacional.

$\checkmark$ Con la aplicación del principio de destino, el país estaría cumpliendo una de las recomendaciones hechas por la OCDE (2003) en las Directrices sobre comercio electrónico, además de coadyuvar al cumplimiento del objetivo de ser parte de este organismo.

$\checkmark$ La modificación del hecho generador del IVA (Art. 420 del ET) en relación con los servicios prestados desde el exterior plantea problemas de territorialidad; a diferencia de los bienes donde el ingreso del impuesto se hace por la aduana y es fácil delimitar las fronteras, los servicios, por carecer de soporte material, requieren otro tipo de tratamiento.

$\checkmark$ Como mecanismos de recaudo del IVA en los servicios transfronterizos, la reforma tributaria (Ley 1819 de 2016) resolvió que en todos los servicios que adquieran los del régimen común, el recaudo se hace vía retención por el adquiriente, criterio que resulta eficaz, mientras que para los no responsables de este régimen, plantea dos condiciones; una, solo para los servicios electrónicos o digitales del numeral $8 \mathrm{del}$ Art. 437-2 del ET, en donde el recaudo se hace por medio de los prestadores de servicios que están en el exterior, y si estos incumplen, opera la retención a través de los medios de pago a partir del 1 de julio de 2018; la segunda, para los demás servicios donde el adquiriente no es del régimen común, supone para los prestadores de servicios desde el exterior la responsabilidad por el IVA entre ellas, la de declarar y pagar al Estado colombiano dicho impuesto. 
$\checkmark$ Respecto a los proveedores extranjeros, como responsables del IVA, hacer efectivo el recaudo y la observancia de las obligaciones no formales por parte de estos es una tarea que suscita complejidad por varios factores, principalmente por la identificación del cliente, ubicación, conocimiento de la normatividad, costos de cumplimiento, aplicación de sanciones en caso de incumplimiento por parte del proveedor de los servicios, entre otros.

$\checkmark$ Cuando los servicios se prestan a consumidores finales no pertenecientes al régimen común y dependiendo de la reglamentación que establezca la DIAN para la aplicación del IVA por parte de los proveedores extranjeros o para los agentes de retención, los efectos pueden ser contrarios a los que pretende la ley e ir en contravía del principio de neutralidad del impuesto porque los proveedores del exterior pueden optar por infringir la ley o no prestar el servicio y ante esta circunstancia quedar los proveedores nacionales en desventaja competitiva, además de ser un obstáculo para el desarrollo del comercio electrónico.

$\checkmark$ Para los agentes de retención a través de los medios de pago, existe expectativa frente a las reglamentaciones que están por desarrollarse por parte de la DIAN, en atención a que las entidades emisoras de tarjetas de crédito y débito no tienen una relación contractual de adquirencia con el consumidor y fue a estos a quienes la ley les otorgó la calidad de agentes retenedores. Así mismo, para aplicar la retención cuando sea del caso, tendrían que contar con una infraestructura robusta de sistemas de información, dada la carga sustancial que tienen para identificar a los usuarios, conocer el tipo de servicio que están pagando y calcular la base gravable sobre la que se aplica la retención.

$\checkmark$ Las dificultades para la aplicación práctica del recaudo del IVA de las que se ha ocupado esta tesis son retos que enfrenta no solo Colombia, sino a nivel global las administraciones tributarias. Por lo pronto, ya existen directrices emitidas por la OCDE relacionadas con la tributación del comercio electrónico y con el diseño de mecanismos efectivos de recaudo del IVA para los servicios transfronterizos cuando el proveedor no está localizado en la jurisdicción del impuesto, pero aún sin resolver bajo normas internacionales cuando se trate de proveedores extranjeros, para que exista una exigencia legal.

$\checkmark$ Encontrar la fórmula para desarrollar un sistema fiscal que grave de manera eficiente, neutra y justa las transacciones digitales en los impuestos indirectos es un desafío, aún nos encontramos en un marco tributario en el que no existe un encaje claro ni en la normativa interna de los países ni en el plano internacional que intente disminuir los efectos fiscales que produce la nueva realidad económica digital; admitiendo que las soluciones a esta problemática no se pueden plantear desde un solo país, sino que deben abordarse a través de acuerdos ampliamente consensuados con diferentes estados.

\section{Referencias}

Anónimo (2017, 31 de octubre). "El próximo año Colombia podría ser parte de la OCDE, según el presidente Santos", en Portafolio. Recuperado el 22 de 01 de 
2018, de http://www.portafolio.co/economia/gobierno/ en-2018-colombia-podria-ser-parte-de-la-ocde-511191.

Bermejo, E. y Conti, L. Infraestructura de datos espaciales (IDE): ¿Qué es y por qué surge? Pamplona, España. Recuperado de https://geoinnova.org/blogterritorio/infraestructura-de-datos-espaciales-ide-quees-y-por-que-surge/.

Cámara Colombiana de Comercio Electrónico. (2016). Comentarios al Proyecto de Ley No. 178 de 2016 Cámara 163 de 2016 Senado "Por medio de la cual se adopta una reforma tributaria estructural, se fortalecen los mecanismos para la lucha contra la evasión y la elusión fiscal, y se dictan otras disposiciones". Recuperado de http://www.imprenta.gov.co/ gacetap/gaceta.mostrar_documento?p_tipo $=1275 \&$ p_ numero $=163 \&$ p_consec $=46856$.

Consejo de Estado, Sala de lo Contencioso Administrativo, Sección Cuarta (14 de julio de 2000) Expediente 9822 (C. P.: Germán Ayala Mantilla).

Consejo de Estado, Sala de lo Contencioso Administrativo, Sección Cuarta (7 de junio de 1996) Expediente 7688 (C. P.: Julio E. Correa Restrepo).

Corte Constitucional, Sala Plena (4 de septiembre de 2000) Sentencia C-1157-00. (M. P.: Antonio Barrera Carbonell). Recuperado de http://www.corteconstitucional.gov.co/relatoria/2000/T-1157-00.htm.

Corte Constitucional, Sala Plena (13 de septiembre de 2000) Sentencia C-1189-00. (M. P.: Carlos Gaviria Díaz). Recuperado de http://www.corteconstitucional. gov.co/relatoria/2000/c-1189-00.htm.

Corte Constitucional, Sala Plena (3 de julio de 2003) Sentencia C-527-03. (M. P.: Álvaro Tafur Galvis). Recuperado de http://www.corteconstitucional.gov.co/ relatoria/2003/C-527-03.htm.

Decisión 599. Gaceta Oficial del Acuerdo de Cartagena Año XXI, número 1093, Lima 16 de julio de 2004. Recuperado de http://intranet.comunidadandina.org/ Documentos/Gacetas/Gace1093.pdf.

Decreto Único Reglamentario en materia tributaria No. 1625, artículo 1.3.1.2.1. (11 de 10 de 2016). Colombia. Recuperado el 25 de 10 de 2017, de http:// www.minhacienda.gov.co/HomeMinhacienda/faces/ oracle/webcenter/portalapp/pagehierarchy/Page203. jspx?_afrLoop=81655033696347\&_afrWindowMode $=0 \&$ \&_frWindowId=null $\$$ ! $\% 40 \% 40 \% 3 \mathrm{~F}$ afrWindowId\%3Dnul1\%26_afrLoop\%3D81655 033696347\%26_afrWindowMode\%3D0\%26_adf.ctrl.
DIAN, Concepto unificado IVA. (19 de 06 de 2003). Características del Impuesto sobre las ventas, 3 . Colombia. Recuperado el 5 de 10 de 2017, de http://www.dian. gov.co/dian/1316Doctrina.nsf/ae6b2064724e74960 525700e006f7fd3/e28f93cf10e199e605256fb10059c ac0?OpenDocument.

DIAN, Oficio No. 657 (17 de mayo de 2013). Recuperado de https://www.dian.gov.co/normatividad/doctrina/ Paginas/DireccionGestionJuridica.aspx.

DIAN, Concepto 28049 (25 de septiembre de 2015). Recuperado de http://as000-011-v3/apl/juridico.nsf/ d96dffc311d071e9052579c3006fe 775/8443295dd5e3 b8ab05257ef20076eb3a?OpenDocument\&Highlight $=0$,septiembre $, 25,2015$.

DIAN, Oficio 013706 (1 de junio de 2017). Recuperado de https://www.dian.gov.co/normatividad/doctrina/ Paginas/DireccionGestionJuridica.aspx.

DIAN, Informe de Rendición de Cuentas de la DIAN (2017). Disponible en: http://www.dian.gov.co/descargas/Rendicioncuentas/2017/Informe_Rendicion_Cuentas_2017_V1.pdf.

Directiva 2006/112/CE del Consejo (Directiva IVA) actualizada a 1 de enero de 2017. Diario Oficial de la Unión Europea, 11 de diciembre de 2006. Recuperado de http://www.agenciatributaria.es/AEAT.internet/ Inicio/La_Agencia_Tributaria/Normativa/Normativa_tributaria_y_aduanera/Impuestos/Impuesto_sobre_el_valor_anadido_IVA_/Normativa_Comunitaria/ Directiva_IVA/Directiva_2006_112_CE__Directiva_IVA_actualizada_a_1_de_enero_de_2017.shtml.

Directiva 2008/8/CE del Consejo, actualizada a enero 1 de 2017. Diario Oficial de la Unión Europea, 11 de diciembre de 2006. Recuperado de http://www. agenciatributaria.es/static_files/AEAT/Contenidos_Comunes/La_Agencia_Tributaria/Normativas/Ficheros_Asociados_a_Las_Normativas/IVA/Texto_Directiva_IVA.pdf.

Lamensch, M. (2012). "Are 'reverse charging' and the 'one-stop-scheme' efficient ways to collect VAT on digital supplies?", in World Journal of VAT/ GST Law. Volume 1 issue 1. doi: 10.5235/WJOVL.1.1.1. Recuperado de https://lirias.kuleuven.be/ bitstream/123456789/547425/3/WJVGL1.1.pdf.

LEGIS (2017). Estatuto Tributario 2017. Colombia: LEGIS.

Ley 527. Diario Oficial No.43.673, Bogotá, Colombia, 21 de agosto de 1999. Recuperado de http://www.se- 
cretariasenado.gov.co/senado/basedoc/ley_0527_1999. html.

Ley 1819. Diario Oficial No. 50.101, Bogotá, Colombia, 29 de diciembre de 2016. Recuperado de http://www.secretariasenado.gov.co/senado/basedoc/ ley_1819_2016.html

Ley No. 23.349. Ministerio de Justicia y Derechos Humanos. Presidencia de la Nación. Buenos Aires, Argentina, 7 de agosto de 1986. Recuperado de http:// servicios.infoleg.gob.ar/infolegInternet/anexos/4000044999/42701/texact.htm.

Marín, M. (2015). "La estructura jurídica del tributo: El hecho generador", en Piza, J. (ed.). La obligación tributaria y sus fundamentos constitucionales, pp. 311-343. Bogotá: Universidad Externado de Colombia.

Ministerio de Hacienda y Crédito Público (2016). minhacienda.gov.co. Obtenido de http://www.minhacienda.gov.co/HomeMinhacienda/ShowProperty? nodeId $=\% 2$ FOCS $\% 2$ FP_MHCP_WCC-059072\%2F\%2Fi dcPrimaryFile\&revision=latestreleased.

OCDE (2014). Proyecto OCDE/G20 de Erosión de la Base Imponible y Traslado de Beneficios. Cómo abordar los desafíos fiscales de la Economía Digital. Acción 1: Objetivo del 2014. Recuperado de https://www.oecd. $\mathrm{org} / \mathrm{ctp} /$ Action-1-Digital-Economy-ESP-Preliminaryversion.pdf.

OCDE (2015). Proyecto OCDE/G20 sobre la Erosión de la Base Imponible y el Traslado de Beneficios. Resúmenes Informes Finales. Recuperado de https://www.oecd. org/ctp/beps-resumenes-informes-finales-2015.pdf.

OECD (1998). Electronic Commerce: Taxation Framework Conditions. A Report by the Committee on Fiscal Affairs, as presented to Ministers at the OECD Ministerial Conference, "A Borderless World: Rea- lising the Potential of Electronic Commerce" on 8 October 1998.

OECD (2001). Taxation and Electronic Commerce Taxation and Electronic Commerce. Implementing the Ottawa Taxation Framework Conditions. Recuperado de https://www.oecd.org/tax/consumption/Taxation\%20and\%20eCommerce\%202001.pdf

OECD (2017). "Model Tax Convention on Income and on Capital: Condensed Versión 2017", in OECD publishing.http://dx.doi.org/10.1787/mtc_cond-2017-en.

OECD (2017). "International VAT/GST Guidelines", in OECD Publishing, Paris. http://dx.doi.org/10.1787/978 9264271401-en.

OECD (2017). Mechanisms for the Effective Collection of VAT/GST. Where the Supplier is not located in the jurisdiction of taxation. Recuperado de https://www. oecd.org/tax/tax-policy/mechanisms-for-the-effectivecollection-of-VAT-GST.pdf.

ONU: UNCTAD/IER (2015). "Informe sobre la economía de la información 2015 - Liberar el potencial del comercio electrónico para los países en desarrollo". Conferencia de las Naciones Unidas sobre comercio y desarrollo UNCTAD. Recuperado de http://unctad.org/es/ paginas/PublicationWebflyer.aspx?publicationid=1146. Consultado en febrero 12 de 2018.

Quaderno (2016, 12 de julio). Los impuestos digitales a través del mundo. Recuperado de https://quaderno.io/ es/blog/impuestos-digitales-traves-del-mundo/.

Villanueva, W. (2014). "Los hechos gravados en el IVA en el derecho comparado", en Revista Derecho PUCP (72), Facultad de Derecho PUCP, 2014, pp. 223-239. Recuperado de http://revistas.pucp.edu.pe/index.php/ derechopucp/article/view/9776/10187. 